\title{
O Uso de Mapas Conceituais como Instrumento de Ensino e Avaliação da Aprendizagem Significativa dos Conceitos Relacionados a Química do Petróleo
}

\author{
Sandralice Marins da Silva Dias*, Wagner da Silva Terra**
}

\section{Resumo}

O Ensino de Química é comumente estruturado em torno de atividades que levam à memorização de informações e repetição mecânica de conceitos, o que pode culminar na limitação do aprendizado dos alunos. Dentro deste contexto, é necessário procurar executar novas propostas e estratégias de ensino e aprendizagem, assim como materiais e instrumentos potencialmente significativos, a fim de viabilizar a amplificação da qualidade do ensino. Nesta perspectiva, Mapas Conceituais apresentam-se como instrumentos flexíveis e dinâmicos, que podem ser utilizados em sala de aula ou laboratório. Deste modo, o objetivo principal deste trabalho foi a utilização de Mapas Conceituais com intuito de contribuir para uma aprendizagem mais significativa dos alunos da parte experimental da disciplina de "Tecnologias Regionais II" do Curso Técnico em Química do Instituto Federal Fluminense (IFFluminense) campus Campos Centro. Os mapas foram elaborados a partir do software CmapTools, e posteriormente anexados ao material didático de duas turmas do módulo IV do Curso Técnico em Química, os quais foram utilizados durante o segundo semestre letivo de 2018. Em busca de evidências da eficácia da utilização dos Mapas Conceituais para contribuir para uma aprendizagem mais significativa, foi introduzido um Questionário de Opinião contendo perguntas mistas a fim de detectar a percepção dos discentes acerca do instrumento de ensino utilizado. Mapas Conceituais também foram utilizados como instrumentos de avaliação, os quais foram elaborados pelos estudantes em três momentos distintos, sendo estes, ao início do semestre e ao final do primeiro e segundo bimestres. Esses mapas tinham intuito de procurar indícios que apontassem para uma aprendizagem

* Licenciada em Ciências e Química pelo Instituto Federal Fluminense - IFFluminense campus Campos Centro. Brasil. E-mail: dsandralice@gmail.com.

* Doutor em Ciências Naturais - UENF. Professor do curso de Licenciatura em Ciências e Química do Instituto Federal Fluminense - IFFluminense campus Campos Centro. R. Dr. Siqueira, 273 - Parque Dom Bosco, Campos dos Goytacazes - RJ, 28030-130. Brasil. E-mail: wagnerdasilvaterra@yahoo.com.br.

Recebido em: 09/05/2020; Aceito em: 22/04/2021

https://doi.org/10.5335/rbecm.v4i2.10989

http://creativecommons.org/licenses/by-nc-nd/4.0

ISSN: 2595-7376 
mais significativa, assim como, averiguar a evolução conceitual dos discentes. Por meio da análise dos questionários e dos Mapas Conceituais elaborados pelos educandos, observou-se, de modo geral, uma evolução conceitual progressiva e sinais apontando para uma aprendizagem mais significativa, além de indicar que materiais potencialmente significativos podem contribuir para auxiliar no processo de ensino e aprendizagem.

Palavras-chave: Aprendizagem Significativa. Ensino de Química. Mapas Conceituais.

\section{Introdução}

O Ensino de Química é comumente estruturado em torno de atividades que levam à memorização de informações, sendo majoritariamente observada a realização de aulas demasiadamente expositivas e a priorização de ferramentas pedagógicas repetitivas. Essa forma de ensinar, muitas vezes, acaba por promover uma aprendizagem predominantemente mecânica, em detrimento à significativa, culminando na limitação do aprendizado dos alunos (PIVATTO, 2013; SANTOS et al., 2013).

De acordo com Pivatto (2013, p. 3), aprender deve ser entendido como "compreensão de significados relacionados às experiências anteriores e às vivências pessoais dos educandos". Desta forma, uma aprendizagem com mais significado é estimulada, o que contribui para a utilização do que é aprendido em diferentes situações. Dentro desse contexto é relevante evidenciar a Teoria da Aprendizagem Significativa (TAS) de David Paul Ausubel (1963), que tem como cerne a proposta de que os conhecimentos prévios dos alunos carecem ser valorizados e levados em consideração no processo de ensino e aprendizagem. À vista disso:

A aprendizagem é muito mais significativa à medida que o novo conteúdo é incorporado às estruturas de conhecimento de um aluno e adquire significado para ele a partir da relação com seu conhecimento prévio. Ao contrário, ela se torna mecânica ou repetitiva, uma vez que se produziu menos essa incorporação e atribuição de significado, e o novo conteúdo passa a ser armazenado isoladamente ou por meio de associações arbitrárias na estrutura cognitiva (PELIZZARI et al., 2002, p. 2).

Segundo Pelizzari e colaboradores (2002), quanto mais o estudante relaciona o novo conteúdo com algum aspecto relevante previamente presente em sua estrutura cognitiva, mais próximo estará da aprendizagem significativa. Em contrapartida, quanto menos se estabelece esse tipo de relação, mais próximo estará da aprendizagem mecânica ou repetitiva. A aprendizagem significativa apresenta vantagens notáveis em relação à mecânica. Tais vantagens se manifestam tanto do ponto de 
vista do enriquecimento da estrutura cognitiva do aprendiz, bem como do ponto de vista da lembrança posterior, delimitando a aprendizagem significativa como sendo a mais adequada para ser promovida entre os alunos (PELIZZARI et al., 2002).

Diante do que foi declarado, pesquisadores das áreas de educação científica e tecnológica precisam conscientizar-se a respeito da qualidade do processo de ensino e aprendizagem, buscando formas de aprimorá-lo. Deste modo, é necessário procurar implementar novas propostas e estratégias de ensino, a fim de se alcançar uma aprendizagem com maior significado para os discentes. Uma alternativa é a inserção de materiais e instrumentos potencialmente significativos, os quais poderão minimizar a distância entre os conceitos que são aprendidos e os que são ensinados (PACHECO e DAMASIO, 2009; PIVATTO, 2013).

De acordo com Pivatto (2013), existem vários instrumentos que podem contribuir para o processo de ensino e aprendizagem dos discentes, como por exemplo, a utilização e construção de Mapas Conceituais. Esse instrumento educacional tem como finalidade principal auxiliar o desenvolvimento cognitivo dos alunos, englobando a aquisição de conhecimentos e a evolução conceitual desses, possibilitando que ocorra uma reorganização construtiva entre os conceitos preexistentes e os aprendidos.

Os Mapas Conceituais têm se apresentado como uma ferramenta de ação pedagógica muito útil para o ensino de diversos temas, possibilitando que um conjunto de conceitos seja apresentado aos alunos, de tal modo que esses estejam correlacionados entre si. Os mapas de conceitos foram desenvolvidos por Novak e Gowin como uma forma de instrumentalizar a Teoria da Aprendizagem Significativa de David Ausubel (FREITAS FILHO, 2007; RUIZ-MORENO et al., 2007).

Mapas Conceituais são, em um sentido mais amplo, diagramas indicando relações entre conceitos. Mais especificamente, podem ser entendidos como diagramas hierárquicos que procuram refletir a organização conceitual de uma disciplina, ou parte dela. Os Mapas Conceituais influem positivamente no processo de estruturação de conceitos-chave e na fixação dessas concepções nas estruturas cognitivas dos educandos (MOREIRA e ROSA, 1986; ROCHA e SPOHR, 2016).

Tais mapas são recursos flexíveis e dinâmicos, que podem ser utilizados em sala de aula ou laboratório. Ostentam como maior vantagem o fato de auxiliarem no processo de aprendizagem de conceitos, algo que muitas vezes pode ficar perdido em meio a uma grande quantidade de informações e fórmulas. Mesmo as experiências 
laboratoriais não passariam de simples manipulações de objetos caso as concepções não estejam claras, precisas e diferenciadas (MOREIRA e ROSA, 1986).

A título de exemplos de trabalhos que utilizaram os Mapas Conceituais como ferramenta educacional pode-se citar os trabalhos desenvolvidos por Araújo e colaboradores (2006), Freitas Filho (2007) e Lima e colaboradores (2017), os quais são brevemente apresentados a seguir:

Araújo e colaboradores (2006) exploraram o tema “destilação fracionada do petróleo", enfocando a exploração de um tema organizador relacionado ao cotidiano dos alunos, lançando mão da técnica de Mapas Conceituais. Segundo os autores, os conceitos químicos trabalhados no laboratório tornam-se mais efetivos quando técnicas pedagógicas de ensino estão incorporadas. Segundo eles, os professores podem utilizar dessa estratégia de ensino em aulas práticas, em conjunto com um tema organizador apropriado para uma contextualização do cotidiano, com uma atribuição muito positiva da aprendizagem realmente significativa.

Freitas Filho (2007) utilizou Mapas Conceituais como estratégia pedagógica para a análise e organização do conteúdo, assim como, na avaliação da aprendizagem de estudantes dos cursos de Agronomia, Medicina Veterinária e Zootecnia. Segundo o autor, foi uma estratégia pedagógica construída após aulas em sala e em laboratório, cuja maior vantagem foi o fato de enfatizar o ensino e a aprendizagem de conceitos importantes relacionados a química dos carboidratos, lipídios e proteínas.

Lima e colaboradores (2017) avaliaram a contribuição do uso de Mapas Conceituais visando a aprendizagem significativa de conceitos inerentes da Química Orgânica em uma turma de $3 \square$ ano do Ensino Médio regular. Segundo os autores, a estratégia de usar a elaboração de Mapas Conceituais como ferramenta avaliativa da aprendizagem na Química se mostrou interessante, pois convocou o aprendiz a expor sua organização mental e as relações dos conceitos estudados, "permitindo ao aluno hierarquizá-los e (re)significá-los" (LIMA, et al., 2017, p. 48). Já o professor, teve a oportunidade de qualificar a assimilação dos discentes sobre o conteúdo abordado, optando pela análise do processo do ponto de vista do estudante, em detrimento à tradicional avaliação quantitativa. Desta forma, os autores concluíram que o uso de Mapas Conceituais contribuiu efetivamente para uma avaliação formativa, com aspectos que propiciam o desenvolvimento cognitivo dos alunos e a reflexão pelo professor. 
Diante do que foi exposto, lança-se os seguintes questionamentos: Seria possível fazer uso de Mapas Conceituais para compor um material didático potencialmente significativo para uma disciplina de um curso Técnico em Química? Será que a inserção desses instrumentos em uma disciplina experimental de um curso profissionalizante de nível médio poderia proporcionar uma aprendizagem mais significativa? Além disso, será que os referidos mapas poderiam ser utilizados como instrumento para avaliar a evolução conceitual apresentada pelos discentes desse nível de ensino?

Com base no que foi exposto, o presente trabalho teve como objetivo principal contribuir para a aprendizagem significativa dos alunos da parte experimental da disciplina "Tecnologias Regionais II" do Curso Técnico em Química do Instituto Federal Fluminense (IFFluminense) campus Campos Centro, por meio da utilização de Mapas Conceituais como recurso facilitador no processo de ensino e aprendizagem. De forma mais específica, este trabalho visou elaborar um material didático potencialmente significativo, fazendo uso dos Mapas Conceituais como instrumentos para elucidar os conceitos relacionados à disciplina supracitada. Da mesma forma, objetivou empregar o material elaborado em duas turmas do último módulo de um curso profissionalizante de nível médio, com intuito de criar meios para a promoção de uma aprendizagem mais significativa. Por fim, visou utilizar Mapas Conceituais como instrumentos para avaliar a evolução conceitual dos discentes ao longo do semestre, assim como, buscar indícios que apontem para uma aprendizagem mais significativa.

\section{Metodologia}

\section{Tipo de Pesquisa e Público-alvo}

De acordo com os objetivos estabelecidos no presente trabalho, ele estrutura-se como uma pesquisa de caráter qualitativo, visto que se observa uma preocupação com o aprofundamento das compreensões de um grupo social específico, sem a necessidade de quantificação ou avaliação estatística dos dados obtidos (GOLDENBERG, 1997). Portanto o presente trabalho tende a destacar os aspectos dinâmicos, integrais e individuais do público alvo estabelecido, para que por meio desta coleta de dados, seja possível compreender todo o processo baseado nas perspectivas da- 
queles que são submetidos aos fenômenos analisados (POLIT et al., 2004; SILVEIRA e CÓRDOVA, 2009).

O presente projeto foi desenvolvido ao longo do segundo semestre letivo de 2018 e direcionado a duas turmas do Curso Técnico em Química do Instituto Federal Fluminense (IFFluminense) campus Campos Centro, localizado na Cidade de Campos dos Goytacazes-RJ. Foram envolvidos 29 alunos no projeto, os quais estavam devidamente matriculados na parte experimental da disciplina "Tecnologias Regionais II" (três tempos de 50 minutos por semana) do quarto módulo do referido curso. Essa componente curricular é direcionada ao ensino de conteúdos relacionados à perfuração, produção e análise de petróleo, sendo esses de extrema importância para a economia da Região Norte e Noroeste do Estado do Rio de Janeiro.

\section{Ełapas da Pesquisa}

Antes da intervenção, as turmas do referido curso tinham acesso aos conteúdos da disciplina por meio de 17 experimentos descritivos (Quadro 1). Portanto o material didático oferecido aos discentes somente continha uma breve introdução sobre cada um dos experimentos abordados e a metodologia para confecção de cada um deles. No entanto, a primeira etapa desta pesquisa consistiu na elaboração de Mapas Conceituais referentes a cada um dos 17 experimentos realizados, com intuito de estimular o potencial significativo do referido material. Tais mapas foram elaborados utilizando o software CmapTools e, em seguida, adicionados à apostila da disciplina. Esse software foi selecionado por ser gratuito (http://cmap.ihmc.us/ download/), possuir versão na língua portuguesa e ser de fácil manuseio (CAÑAS et al., 2001; CAÑAS et al., 2004). Os mapas elaborados abrangeram cada prática individualmente, conforme apresentado no Quadro 1. 
Quadro 1: Experimentos presentes na disciplina de "Tecnologias Regionais II" que deram origem aos Mapas Conceituais Elaborados nesta Pesquisa.

\begin{tabular}{|l|l|}
\hline $\mathrm{n}$ & \multicolumn{1}{|c|}{ Experimentos e Mapas Conceituais Elaborados nesta Pesquisa } \\
\hline 1 & Densidade do etanol pelo densímetro de bulbo e densidade do petróleo pelo densímetro digital. \\
\hline 2 & Viscosidade do óleo cru pelo viscosímetro digital DV-1. \\
\hline 3 & Estimativa do teor de asfaltenos em diferentes amostras de petróleo. \\
\hline 4 & $\begin{array}{l}\text { Avaliação de desempenho de desemulsificantes comerciais na separação da água produzida } \\
\text { do petróleo. }\end{array}$ \\
\hline 5 & Água e sedimentos em petróleo (BSW) por centrifugação. \\
\hline 6 & Determinação da salinidade em petróleo bruto. \\
\hline 7 & Determinação do ponto de fulgor do petróleo e de outros combustíveis. \\
\hline 8 & $\begin{array}{l}\text { Teor de óleos e graxas (TOG) por espectrofotometria de absorção molecular e pelo método de } \\
\text { evaporação rotativa. }\end{array}$ \\
\hline 9 & Teor de oxigênio dissolvido na água pelo kit chemets e medidor de oxigênio dissolvido POL-60. \\
\hline 10 & Adensamento e redução da densidade de fluídos de perfuração de poços petrolíferos. \\
\hline 11 & $\begin{array}{l}\text { Caracterização reológica de fluidos e influência de viscosificantes sobre os parâmetros reológi- } \\
\text { cos e gelificantes. }\end{array}$ \\
\hline 12 & Determinação da viscosidade Marsh de um fluido de perfuração. \\
\hline 13 & Determinação do teor de areia de um fluido de perfuração. \\
\hline 14 & $\begin{array}{l}\text { Determinação dos parâmetros de filtração utilizando baixas temperatura e pressão (BTBP) e } \\
\text { determinação da salinidade de um fluido de perfuração à base de água. }\end{array}$ \\
\hline 15 & $\begin{array}{l}\text { Determinação do teor de água, óleo e sólidos por meio da destilação do fluido de perfuração } \\
\text { (retorta do fluido). }\end{array}$ \\
\hline 16 & Estudos sobre a formulação de um fluido de perfuração à base água. \\
\hline 17 & Avaliação da densidade e viscosidade de um fluido de perfuração à base água. \\
\hline
\end{tabular}

${ }^{*} n=$ Número dos Experimentos presentes na disciplina de "Tecnologias Regionais II" do curso Técnico em Química do IFFluminense. Fonte: Elaboração própria

Depois de confeccionados, os Mapas Conceituais foram utilizados pelos alunos da disciplina "Tecnologias Regionais II", durante todo o segundo semestre letivo de 2018. Cabe ressaltar que as aulas se iniciavam de forma teórica e, posteriormente, os alunos realizavam as práticas laboratoriais referentes à teoria. Moreira (2011; 2013) evidencia que é aconselhável fazer uso dos Mapas Conceituais quando os alunos já têm certa familiaridade com o assunto, visto que esses não são autoexplicativos. Desta forma, em cada aula, o professor da disciplina promovia uma explicação teórica do conteúdo e, posteriormente, fazia uso do Mapa Conceitual em conjunto com os alunos, que o acompanhavam na leitura e interpretação do material 
elaborado. Portanto, o mapa serviu como um meio de organizar a matéria de forma simplificada, para que os discentes pudessem realizar a parte procedimental com os conceitos tão elucidados e claros quanto possível.

A segunda etapa desta pesquisa foi direcionada a confecção dos Mapas Conceituais pelos discentes. Esse procedimento foi utilizado como um dos mecanismos de avaliação para a supracitada disciplina, contrapondo as avaliações fechadas que normalmente são utilizadas em cursos profissionalizantes de nível médio. Para verificar a evolução conceitual dos discentes, os mapas foram elaborados em três momentos distintos, a saber, no início do semestre letivo e ao final de cada uma das duas etapas que compõe o semestre, ou seja, $1^{\circ}$ e $2^{\circ}$ bimestres.

O tema "Petróleo" foi selecionado para construção dos Mapas Conceituais em todos os três momentos. Esse foi selecionado por ser o tema principal da disciplina e, além disso, acreditou-se que os discentes possuíam conceitos relevantes preexistentes em suas respectivas estruturas cognitivas (subsunçores), tais como: origem, função, composição química, importância para sociedade e aspectos geopolíticos do petróleo. Além disso, é relevante evidenciar que no primeiro dia do semestre letivo, houve uma aula introdutória, que permitiu que os professores da disciplina apresentassem uma visão geral do que seria trabalhado durante o semestre, destacando temas como: origem do petróleo, características químicas, onde é encontrado, entre outros. Desta forma, todos os alunos que estavam presentes nessa aula empregaram conceitos relacionados ao que foi discutido nesse momento, além dos conceitos que já estavam presentes em suas estruturas cognitivas antes da realização dessa aula. Também é importante salientar que a confecção dos mapas ocorreu na semana posterior ao primeiro dia de aula, sendo realizado um breve relato a respeito dos processos de produção desse instrumento de ensino e avaliação. Tal explicação teve o intuito de familiarizar os educandos com as técnicas básicas para construção de Mapas Conceituais, para que eles pudessem elaborá-los durante a aplicação deste projeto, bem como, construir os seus próprios mapas com o intuito de auxiliá-los em seus respectivos processos de ensino e aprendizagem.

Conforme evidenciam Moreira (2013) e Moreira e Rosa (1986), não existem regras gerais fixas para se traçar Mapas Conceituais, pois o importante é que o mapa seja um instrumento capaz de evidenciar os significados atribuídos aos conceitos e às relações entre eles. Deste modo, optou-se por deixar os estudantes livres para criarem seus mapas conforme o desejassem. Contudo, foi especificado que os con- 
ceitos deveriam ser ordenados hierarquicamente, ou seja, dos conceitos mais gerais para os mais específicos.

\section{Instrumentos para coleta e avaliação dos dados}

A coleta de dados se deu por meio de duas formas. A primeira delas consistiu na obtenção dos Mapas Conceituais elaborados pelos discentes nos três momentos. Esses se configuraram como possíveis ferramentas de avaliação da aprendizagem dos conceitos obtidos no decorrer da disciplina, a qual foi ministrada utilizando as duas ferramentas selecionadas (Mapas Conceituais e Experimentos Descritivos).

Dentre os 29 alunos que realizaram os Mapas Conceituais, 14 construíram os três mapas solicitados, 10 fizeram somente dois e 5 alunos construíram apenas um. Neste sentido, optou-se por apresentar os dados obtidos pela análise dos Mapas Conceituais dos alunos que elaboraram dois, ou os três mapas requisitados. Esse fato foi realizado para que se pudesse analisar a evolução conceitual de um educando por meio dos mapas elaborados. Dentre os 24 alunos que tiveram seus mapas selecionados, um não apresentou características de Mapa Conceitual, pois foi elaborado em forma de texto corrido e tópicos. Esse mapa possuía algumas poucas setas relacionando os textos entre si, com ausência total de palavras de ligação. $O$ aluno em questão construiu todos os mapas com a mesma estrutura, mesmo estando presente na aula em que foram elucidados os processos de construção dos Mapas Conceituais. Desta forma, apenas 23 alunos tiveram os dados dos seus Mapas Conceituais pontuados, os quais foram classificados de A a W.

Depois de selecionados os Mapas Conceituais foram analisados adotando-se os critérios de Novak e Gowin (1996). Esse método de avaliação está de acordo com as características principais apontadas por Moreira (2012), consistindo na avaliação dos seguintes critérios: proposições, hierarquia, ligações cruzadas (ou transversais) e exemplos. De acordo com as características de cada critério classificatório foram concedidas pontuações a cada um dos mapas elaborados pelos discentes de acordo com os valores reportados na literatura (NOVAK e GOWIN, 1996 apud MARTINS et al., 2009, p. 5). É relevante ressaltar que, ao longo da avaliação dos critérios classificatórios, foram contabilizadas como meio certo ( 0,5 ponto) as ligações entre conceitos que não apresentaram palavras de ligação. Desta maneira, quando dois conceitos ligados entre si apresentavam veracidade e coerência em sua relação, 
mas estavam desprovidos de palavras de enlace, atribuiu-se 0,5 ponto, o qual foi posteriormente multiplicado à pontuação referente ao critério classificatório correspondente (Tabela 1$)$.

Tabela 1: Pontuação para os Mapas Conceituais.

\begin{tabular}{l|r}
\hline Critérios classificatórios & Pontuação \\
\hline Proposições (ligações entre dois conceitos): & 1 \\
Cada ligação se for válida e significativa & 5 \\
Hierarquia: cada nível válido & 10 \\
Ligações Transversais: cada ligação se for: & 2 \\
Válida e significativa & 1 \\
Somente válida & 1 \\
Criativa ou peculiar & \\
Exemplos: cada exemplo válido & \\
\hline
\end{tabular}

Fonte: MARTINS et al. 2009.

Os resultados obtidos para cada Mapa Conceitual elaborado pelos discentes foram categorizados em seis faixas de acordo com a pontuação obtida em cada mapa [Faixa 1 (De 0 a 10 pontos) - Desempenho muito baixo; Faixa 2 (De 11 a 20 pontos) - Desempenho baixo; Faixa 3 (De 21 a 30 pontos) - Desempenho moderado; Faixa 4 (De 31 a 40 pontos) - Desempenho alto; Faixa 5 (De 41 a 50 pontos) - Desempenho muito alto; Faixa 6 (Acima de 50 pontos) - Desempenho acima do esperado)]. Essas faixas foram obtidas a posteriori com o intuído de atribuir um conceito aos mapas elaborados, que foram correspondentes à $20 \%$ da pontuação de cada etapa da disciplina.

A segunda forma de coleta de dados se deu pela aplicação de um questionário qualitativo contendo perguntas abertas e fechadas ao final da aplicação do projeto (Quadro 2). O referido questionário teve por intuído coletar informações e opiniões dos alunos a respeito da intervenção realizada. Após respondidos os questionários tiveram suas questões agrupadas por similaridade e discutidas com base no referencial teórico. 
Quadro 2: Questionário de Opinião aplicado aos discentes ao final da aplicação deste projeto.

\begin{tabular}{|c|c|}
\hline \multicolumn{2}{|r|}{$\begin{array}{l}\text { Prezado(a) aluno(a), gostaríamos muito de contar com sua participação neste trabalho. } \\
\text { Por meio da realização deste questionário poderemos analisar a importância da utilização de Mapas } \\
\text { Conceituais no processo de ensino e aprendizagem. }\end{array}$} \\
\hline & Antecipadamente agradecemos toda sua colaboração. \\
\hline $\mathrm{N}^{\circ}$ & Questões \\
\hline 1 & $\begin{array}{l}\text { Você já conhecia a ferramenta Mapa Conceitual? } \\
\begin{array}{lll}\text { ( ) Sim. } & \text { ( ) Não. } & \text { ( ) Prefiro não opinar. }\end{array}\end{array}$ \\
\hline 2 & $\begin{array}{l}\text { Você acredita que o uso dessa ferramenta contribuiu para um melhor entendimento do con- } \\
\text { teúdo? } \\
\text { Caso sua resposta seja sim ou não, justifique. } \\
\begin{array}{lll}\text { ( ) Sim. } & \text { ( ) Não. } & \text { ( ) Prefiro não opinar. }\end{array}\end{array}$ \\
\hline 3 & 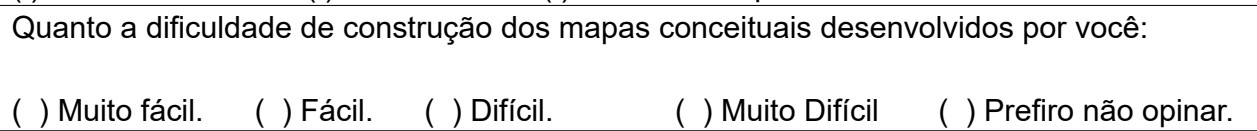 \\
\hline 4 & $\begin{array}{l}\text { Deixe aqui um pequeno comentário sobre a sua experiência com o nosso projeto. Obs:: } \\
\text { Você pode fazer um comentário geral sobre a atividade desenvolvida, se gostou ou não, } \\
\text { mostrar pontos positivos e negativos, dar sugestões e outros. }\end{array}$ \\
\hline
\end{tabular}

Fonte: Elaboração própria

Também é pertinente salientar, que os alunos S e P não responderam ao Questionário de Opinião aplicado ao final do semestre letivo, o que inviabilizou a relação das respostas desses alunos com seus respectivos Mapas Conceituais. Ambos os discentes abandonaram o curso após o primeiro bimestre, o que justifica o fato de não terem respondido ao esse questionário e nem elaborado o último mapa solicitado. Porém os mapas desses dois alunos foram contabilizados para avaliação da primeira parte da disciplina, visto que ambos apresentaram dois mapas, o elaborado no início do semestre e o realizado ao final do $1^{\circ}$ bimestre. Desta forma, dos 23 alunos que tiveram seus mapas corrigidos, 21 responderam ao questionário supracitado. 


\section{Resultados e discussão}

\section{Elaboração e Utilização de Mapas Conceituais como Ferramenta Facilitadora da Aprendizagem}

Os Mapas Conceituais elaborados pelos docentes da disciplina foram desenvolvidos a fim de serem utilizados como uma ferramenta facilitadora da aprendizagem, proporcionando a organização e elucidação dos conceitos mais importantes abordados no componente curricular. Portanto, por meio desta pesquisa foi possível verificar se a ferramenta utilizada contribuiu para que os alunos encontrassem maior facilidade em discernir a estrutura de significados aceitos no contexto da matéria de ensino da disciplina.

No traçado dos mapas utilizou-se figuras geométricas específicas, apesar de essas não serem determinantes para confecção de um Mapa Conceitual. Preferencialmente conceitos mais abrangentes devem estar destacados no mapa, de tal modo que o leitor consiga diferenciá-lo dos demais (MOREIRA, 2013). Neste trabalho adotou-se elipses com palavras em negrito para indicar o conceito principal e retângulos para indicar conceitos mais específicos, todos conectados por palavras de ligação, as quais dão sentido a conexão existente entre dois conceitos, assim como é possível observar nos dois exemplos de Mapas Conceituais elaborados neste trabalho (Figuras 1 e 2). Além disso, em alguns mapas traçados pelos docentes foram utilizados retângulos verdes para destacar conceitos secundários de maior importância e abrangência, como observado na Figura 1. Esse artifício foi implementando em Mapas Conceituais que apresentavam muitas ligações transversais, o que possibilitou uma maior facilidade de leitura por parte dos discentes. 
Figura 1: Mapa Conceitual direcionado ao Experimento de número 3 (Estimativa do teor de asfaltenos em diferentes amostras de petróleo $-1^{\circ}$ bimestre) - Exemplo 1 dos 17 Mapas Conceituais elaborados neste trabalho.

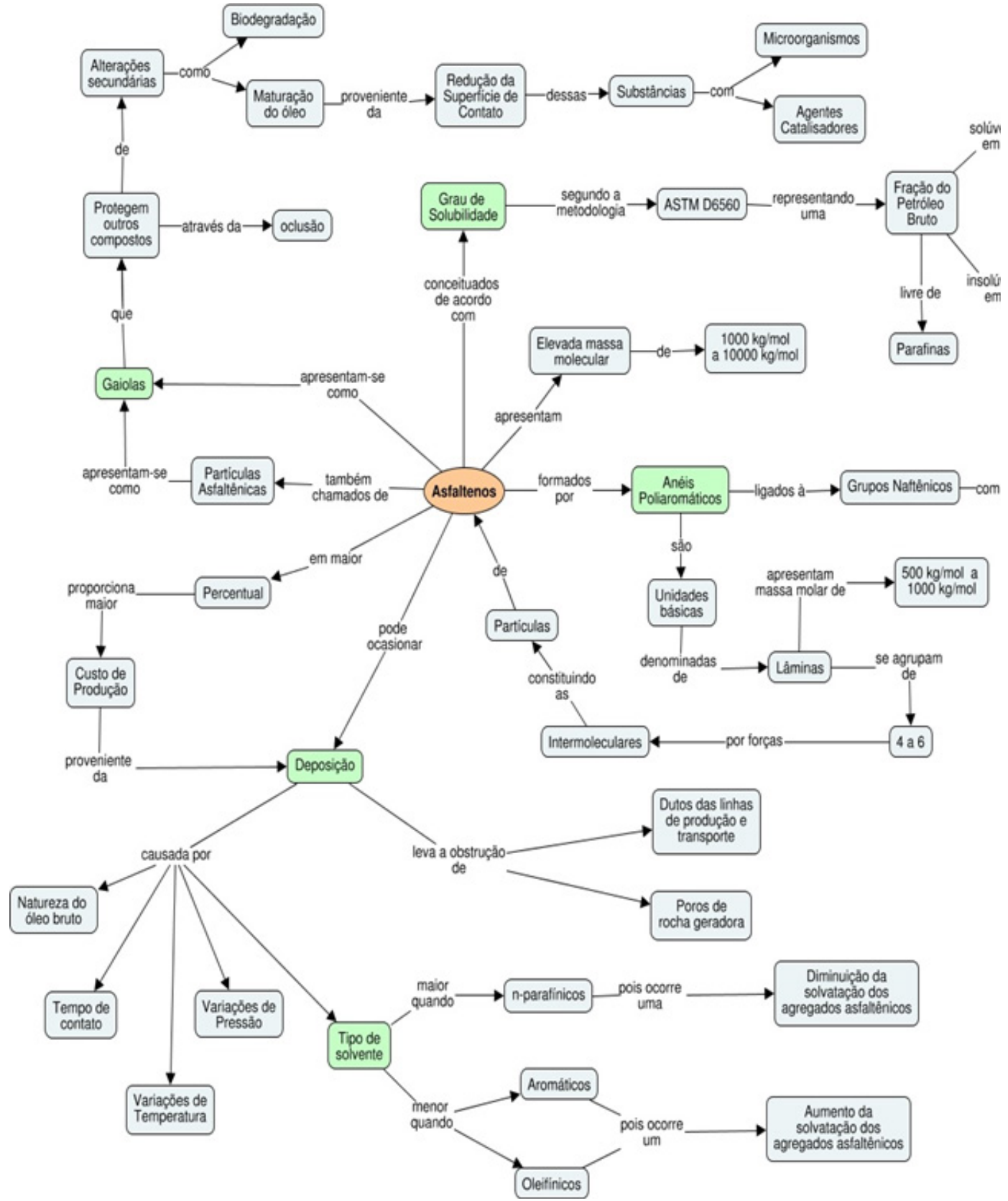


Figura 2: Mapa Conceitual direcionado ao Experimento de número 14 (Determinação dos parâmetros de filtração utilizando baixas temperatura e pressão (BTBP) e determinação da salinidade de um fluido de perfuração à base de água - $2^{\circ}$ bimestre) - Exemplo 2 dos 17 Mapas Conceituais elaborados neste trabalho.

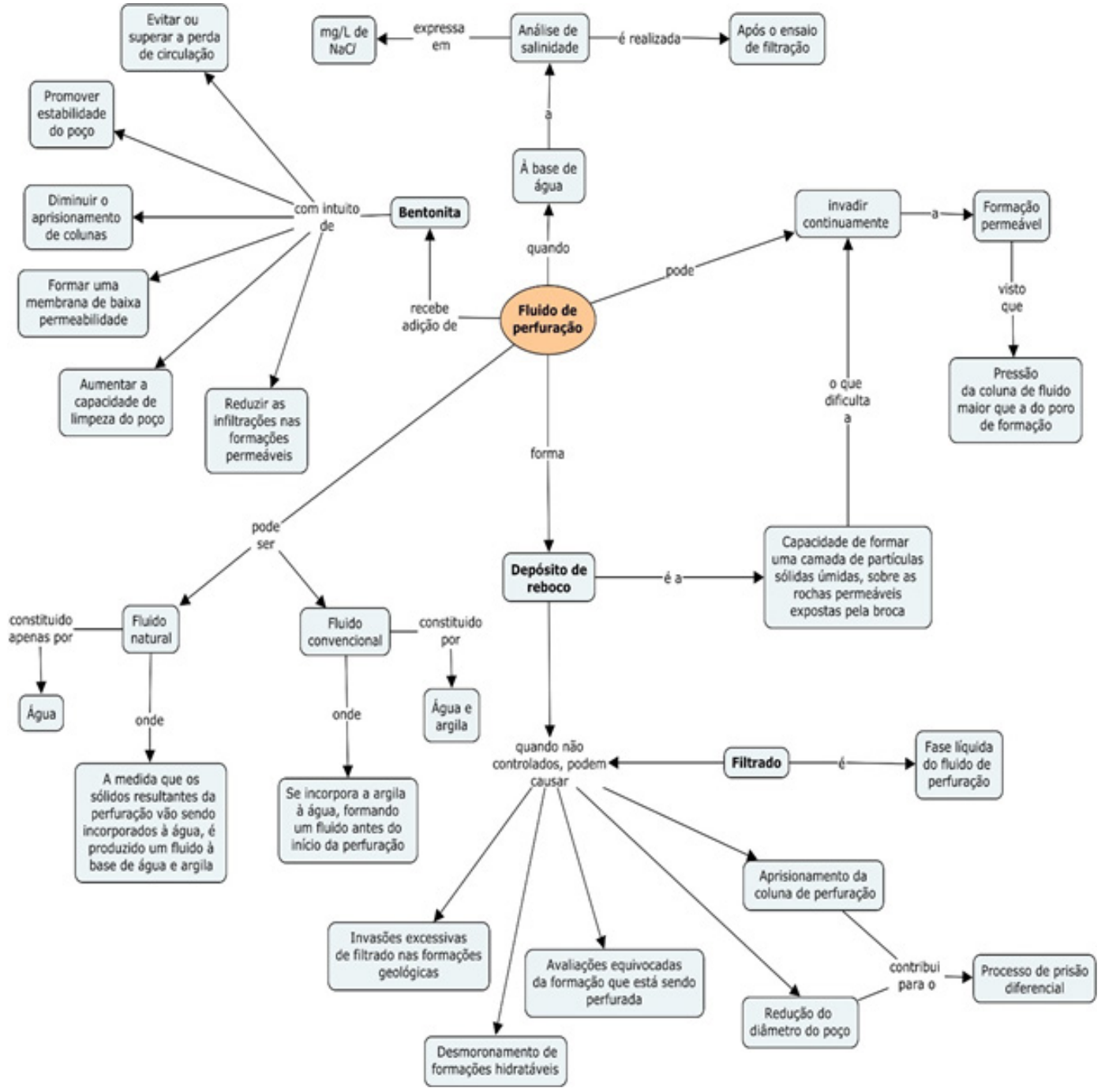

Ao final do semestre letivo, ou seja, após serem utilizados todos os Mapas Conceituais elaborados, os alunos foram questionados, por meio de um questionário contendo perguntas abertas e fechadas, sobre a intervenção realizada. As questões iniciais desse mecanismo de avaliação eram direcionadas a primeira etapa desta pesquisa, sendo possível compreender a opinião dos discentes no que se refere a contribuição dos mapas elaborados. 
Na primeira questão do Questionário de Opinião, os discentes foram indagados se antes da aplicação desta proposta de ensino já conheciam a ferramenta utilizada. Dentre os 21 respondentes, 12 alunos responderam "sim" (57\%) e 9 declararam que "não" (43\%). Ao analisar esses números, pode-se verificar que grande parte dos discentes já conhecia a ferramenta utilizada, porém durante as aulas percebeu-se que eles não possuíam prática na confecção ou leitura desses mapas, sendo assim, possivelmente, alguns discentes confundiram Mapas Conceituais com fluxogramas ou, até mesmo, com Mapas Mentais, ambos muito comuns no dia-a-dia dos estudantes.

Na Questão 2, os alunos foram questionados se o uso dos Mapas Conceituais que compunham seu material didático contribuiu para um melhor entendimento dos conteúdos trabalhados. Dos 21 respondentes, 18 relataram que "sim", 2 responderam "não" e apenas 1 estudante declarou "prefiro não opinar". A análise desses números indica que a maior parte dos estudantes acredita que o uso dos Mapas Conceituais elaborados pelos docentes auxiliou no entendimento dos conteúdos da referida disciplina. Esses dados estão de acordo com relatos apresentados por Moreira (2012) e Trindade e Hartwig (2012), que destacaram que a supracitada ferramenta educacional apresenta potencial como recurso instrucional, facilitando a apresentação e o entendimento de um determinado tópico. Ademais, foi solicitado aos educandos que justificassem suas respostas, que estão apresentadas no Quadro 3.

Quadro 3: Justificativas apresentadas por alguns discentes para a questão número 2 do Questionário de Opinião.

(continua...)

\begin{tabular}{|l|l|}
\hline Aluno & Justificativa \\
\hline A & $\begin{array}{l}\text { "O mapa ajuda a focar em conhecimentos mais importantes de forma dinâmica, o que melhora o } \\
\text { aprendizado." }\end{array}$ \\
\hline B & --- \\
\hline C & "O mapa conceitual ajuda no raciocínio e principalmente na organização para os estudos." \\
\hline D & $\begin{array}{l}\text { "Acredito que contribuiu para um melhor entendimento porque faz uso de "palavras-chaves', nos } \\
\text { ajudando a lembrar dos pontos importantes." }\end{array}$ \\
\hline E & "Auxílio para as provas." \\
\hline F & "Facilita no entendimento e auxilia no estudo para um melhor desempenho." \\
\hline G & $\begin{array}{l}\text { "Sim, porque da para fazer um "resumão" da matéria toda, assim fica melhor para relacionar o } \\
\text { conteúdo." }\end{array}$ \\
\hline H & "Sim, pois ajuda a entender a matéria e não fica tudo embolado." \\
\hline I & "Os mapas conceituais facilitam na compreensão do conteúdo." \\
\hline J & "E uma forma de estudar e revisar a matéria de maneira prática, ajuda a fixar conceitos." \\
\hline K & "O Mapa Conceitual permite realizar um rápido estudo, de forma bem resumida." \\
\hline
\end{tabular}


(conclusão)

\begin{tabular}{|l|l|}
\hline $\mathrm{L}$ & $\begin{array}{l}\text { "Ele destaca os pontos importantes, resume a matéria ajudando a organizar as informações dando } \\
\text { uma melhor compreensão." }\end{array}$ \\
\hline $\mathrm{M}$ & "Acredito que existam explicações mais elaboradas e, particularmente, mais eficientes." \\
\hline $\mathrm{N}$ & "Sim, porque é um jeito mais fácil de resumir o conteúdo, fixa melhor." \\
\hline $\mathrm{O}$ & "Ajudou para um melhor entendimento, facilitando o estudo." \\
\hline $\mathrm{Q}$ & --- \\
\hline $\mathrm{R}$ & "Sim, porque com os mapas conceituais auxilia na hora de estudar e entender a matéria." \\
\hline $\mathrm{T}$ & "Fica mais fácil de acompanhar o raciocínio, de visualizar conceitos e de entender a prática." \\
\hline $\mathrm{U}$ & --- \\
\hline $\mathrm{V}$ & $\begin{array}{l}\text { "Os Mapas Conceituais ajudam a estabelecer uma linha lógica de estudo, principalmente quando } \\
\text { feito pela mesma pessoa que estuda o conteúdo, pois os Mapas Conceituais também são uma } \\
\text { boa forma de revisão." }\end{array}$ \\
\hline $\mathrm{W}$ & "Ajuda a assimilar o conteúdo e ajuda a memorizar as sequências ou etapas." \\
\hline
\end{tabular}

Nota: Os alunos S e $\mathrm{P}$ não realizam o Questionário de Opinião, pois evadiram no $2^{\circ}$ bimestre do curso.

Dentre as justificativas apresentadas no Quadro 3, destacam-se as que apontaram que o uso dos Mapas Conceituais contribuiu para um melhor entendimento do conteúdo, pois "organiza as informações (Aluno C) e direciona os discentes para os "conhecimentos mais importantes (aluno A)". Essas justificativas estão de acordo com Moreira (2012), que destaca que os Mapas Conceituais são instrumentos capazes de evidenciar os significados atribuídos aos conceitos e as relações entre eles, e o fazem de forma objetiva, visualmente organizada e ocupando um espaço reduzido. Outros alunos salientaram que o uso dos Mapas Conceituais proporciona um mecanismo de revisão dos conteúdos de forma simplificada e prática (Alunos G, J, K, L, N e R). Isso se justifica, pois, segundo Moreira (2013) e Moreira e Rosa (1986), sempre devem ficar claro no mapa quais são os conceitos mais importantes e quais os secundários, o que facilita uma posterior revisão do conteúdo de forma rápida.

Dentre as respostas apresentadas anteriormente a do aluno D também merece destaque: "Acredito que contribuiu para um melhor entendimento porque faz uso de 'palavras-chaves', nos ajudando a lembrar dos pontos importantes”. Dentro desse contexto, no que se refere à estrutura dos Mapas Conceituais, é relevante ressaltar que as palavras-chave são importantes para explicitar a natureza da relação que se deseja apontar (MOREIRA e ROSA, 1986; MOREIRA, 2013). Desta forma, o uso de palavras de enlace deve ser incentivado no processo de construção de Mapas Conceituais, de tal modo que a conexão entre os conceitos seja especificada pelo discente. Esse fato somado ao comentário do aluno V, que relatou que "os Mapas Conceituais ajudam a estabelecer uma linha lógica de estudo, principalmente quando feito pela 
mesma pessoa que estuda o conteúdo" indica que a confecção dessa ferramenta educacional também pode auxiliar o processo de ensino e aprendizagem (MOREIRA et al., 2008; DANTAS, et al., 2017; MARTINS, 2009a; MARTINS et al., 2009b).

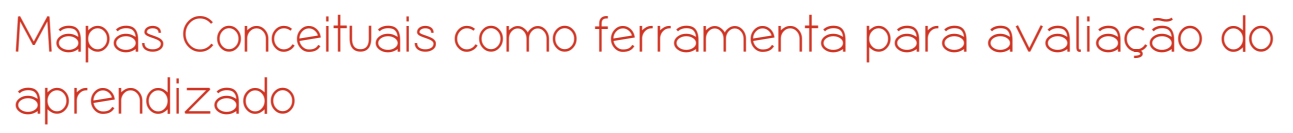

Mapas Conceituais podem ser úteis como ferramenta para avaliação do aprendizado, pois possibilitam que o docente aponte ponderações relacionadas a estrutura proposicional apresentada pelo discente (NOVAK e GOWIN, 1996; PIVATTO, 2013). Esta ferramenta de ensino apresenta grande potencial para a promoção e verificação da diferenciação progressiva e da reconciliação integrativa de conceitos, dado que, as conexões horizontais nos mapas simbolizam o estabelecimento de relações transversais entre os conceitos, característica da reconciliação integrativa. Já a hierarquização é característica da diferenciação progressiva, a qual se observa no mapa quando se "desce" dos conceitos e proposições mais gerais para os mais específicos (MOREIRA, 2012; 2013).

Portanto, os Mapas Conceituais podem ser instrumentos que possibilitam que os professores detectem evidências que apontem para uma aprendizagem mais significativa. Deste modo, a análise da presença de ligações transversais e níveis hierárquicos no Mapa Conceitual elaborado pelo aluno refletem a realização de reconciliação integrativa e diferenciação progressiva, processos esses que fazem parte da dinâmica da estrutura cognitiva e ocorrem no curso da aprendizagem significativa (MOREIRA, 2012; 2013). Somado a esse fato, as palavras de ligação, escritas sobre as linhas que conectam proposições válidas, também podem apontar evidências desse tipo de aprendizagem, pois essas são importantes para explicitar a natureza da relação que o discente deseja apontar, demonstrando que a referida relação está nítida na sua estrutura cognitiva (MOREIRA e ROSA, 1986; MOREIRA, 2012). De maneira oposta, a ausência de palavras de enlace entre dois conceitos pode indicar que a conexão entres as proposições não está totalmente clara na estrutura de conhecimento de quem confeccionou o mapa. Em outros casos, essa ausência pode apontar que o elaborador encontrou dificuldades em expressar relações entre as proposições, ou ainda, simplesmente as esqueceu. 
Desta forma, os Mapas Conceituais elaborados pelos alunos foram avaliados levando em conta os critérios propostos por Novak e Gowin (1996), os quais foram detalhados na metodologia deste trabalho. Essa avaliação teve por intuito pontuar os mapas elaborados pelos discentes, a fim de verificar se esses podem ser utilizados ou não como instrumentos de avaliação no ensino profissionalizante de nível médio. A utilização dos critérios de pontuação dos Mapas Conceituais é uma necessidade apontada tanto por discentes como por docentes, sendo possível fazer uma avaliação da progressão da aprendizagem baseando-se na teoria cognitiva de Ausubel (MARTINS et al., 2009a).

As pontuações obtidas após a análise dos mapas construídos pelos alunos estão dispostas nas Tabelas 2 e 3. Em seguida observa-se uma breve análise de alguns Mapas Conceituais confeccionados pelo público alvo desta pesquisa, a qual irá ressaltar evidências que apontem para uma evolução conceitual dos discentes. Tal análise será direcionada aos Mapas Conceituais elaborados no início das atividades acadêmicas e ao final do primeiro e segundo bimestres, de modo que se possa fazer um estudo comparativo entre os mapas elaborados. É pertinente evidenciar que, como a estrutura cognitiva está constantemente se reorganizando por diferenciação progressiva e reconciliação integrativa, mapas traçados hoje serão diferentes amanhã (MOREIRA, 2012). Desta forma, almeja-se que a estrutura de conhecimento dos educandos evolua ao longo do semestre letivo, e que os Mapas Conceituais traçados por eles apresentem-se como um reflexo dessa evolução.

Tabela 2: Pontuação obtida após análise dos Mapas Conceituais construídos pelos alunos de A a L. (continua...)

\begin{tabular}{l|c|c|c|c|c|c|c|c|c|c}
\hline \multicolumn{1}{c|}{ Aluno } & \multicolumn{3}{c|}{$\mathrm{A}$} & \multicolumn{3}{c|}{$\mathrm{B}$} & \multicolumn{3}{c}{$\mathrm{C}$} \\
\hline \multicolumn{1}{c|}{ Critérios $^{1}$} & Inicial & $1^{\circ} \mathrm{B}^{2}$ & $2^{\circ} \mathrm{B}^{3}$ & Inicial & $1^{\circ} \mathrm{B}^{2}$ & $2^{\circ} \mathrm{B}^{3}$ & Inicial & $1^{\circ} \mathrm{B}^{2}$ & $2^{\circ} \mathrm{B}^{3}$ \\
\hline Proposições válidas e significativas & 10 & 24 & 25 & 5 & 4,5 & 9,5 & 2 & 6,5 & 8,5 \\
\hline Hierarquia: cada nível válido & 20 & 30 & 30 & 10 & 7,5 & 30 & 5 & 5 & 20 \\
\hline $\begin{array}{l}\text { Ligações transversais válidas e } \\
\text { significativas }\end{array}$ & 0 & 20 & 0 & 0 & 0 & 0 & 0 & 0 & 0 \\
\hline Ligações transversais válidas & 0 & 2 & 0 & 0 & 0 & 0 & 0 & 0 & 0 \\
\hline Ligações transversais criativas & 0 & 0 & 0 & 0 & 0 & 0 & 0 & 0 & 0 \\
\hline Exemplos válidos & 0 & 0 & 0 & 0 & 0 & 0 & 0 & 0 & 0 \\
\hline Total & 30 & 76 & 55 & 15 & 12 & 39,5 & 7 & 11,5 & 28,5 \\
\hline
\end{tabular}


(conclusão)

\begin{tabular}{l|c|c|c|c|c|c|c|c|c|c}
\hline \multicolumn{1}{c|}{ Aluno } & \multicolumn{3}{c|}{$\mathrm{D}$} & \multicolumn{3}{c|}{$\mathrm{E}$} & \multicolumn{3}{c}{$\mathrm{F}$} \\
\hline \multicolumn{1}{c|}{ Critérios $^{1}$} & Inicial & $1^{\circ} \mathrm{B}^{2}$ & $2^{\circ} \mathrm{B}^{3}$ & Inicial & $1^{\circ} \mathrm{B}^{2}$ & $2^{\circ} \mathrm{B}^{3}$ & Inicial & $1^{\circ} \mathrm{B}^{2}$ & $2^{\circ} \mathrm{B}^{3}$ \\
\hline Proposições válidas e significativas & 5,5 & 16 & 16,5 & 8 & 14 & 24 & 21,5 & 33 & 29 \\
\hline Hierarquia: cada nível válido & 15 & 15 & 22,5 & 15 & 15 & 22,5 & 17,5 & 25 & 30 \\
\hline $\begin{array}{l}\text { Ligações transversais válidas e } \\
\text { significativas }\end{array}$ & 0 & 0 & 0 & 0 & 10 & 10 & 0 & 0 & 0 \\
\hline Ligações transversais válidas & 0 & 0 & 0 & 0 & 0 & 0 & 0 & 0 & 0 \\
\hline Ligações transversais criativas & 0 & 0 & 0 & 0 & 0 & 0 & 0 & 0 & 0 \\
\hline Exemplos válidos & 0 & 0 & 0 & 3 & 3 & 3 & 7 & 8 & 0 \\
\hline Total & 20,5 & 31 & 39 & 26 & 42 & 59,5 & 46 & 66 & 59 \\
\hline
\end{tabular}

\begin{tabular}{l|c|c|c|c|c|c|c|c|c|c}
\hline Aluno & \multicolumn{3}{|c|}{$\mathrm{G}$} & \multicolumn{3}{c|}{$\mathrm{H}$} & \multicolumn{3}{c}{$\mathrm{I}$} \\
\hline Critérios $^{1}$ & Inicial & $1^{\circ} \mathrm{B}^{2}$ & $2^{\circ} \mathrm{B}^{3}$ & Inicial & $1^{\circ} \mathrm{B}^{2}$ & $2^{\circ} \mathrm{B}^{3}$ & Inicial & $1^{\circ} \mathrm{B}^{2}$ & $2^{\circ} \mathrm{B}^{3}$ \\
\hline Proposições válidas e significativas & 6 & 11,5 & 14,5 & 7 & 21 & 25 & 6,5 & 21,5 & 18 \\
\hline Hierarquia: cada nível válido & 10 & 10 & 15 & 10 & 20 & 25 & 10 & 17,5 & 22,5 \\
\hline $\begin{array}{l}\text { Ligações transversais válidas e } \\
\text { significativas }\end{array}$ & 0 & 0 & 0 & 0 & 10 & 0 & 0 & 10 & 0 \\
\hline Ligações transversais válidas & 0 & 0 & 0 & 0 & 0 & 0 & 0 & 0 & 0 \\
\hline Ligações transversais criativas & 0 & 0 & 0 & 0 & 1 & 0 & 0 & 0 & 0 \\
\hline Exemplos válidos & 0 & 0 & 0 & 0 & 0 & 2 & 0 & 2 & 1 \\
\hline Total & 16 & 21,5 & 29,5 & 17 & 52 & 52 & 16,5 & 51 & 41,5 \\
\hline
\end{tabular}

\begin{tabular}{l|c|c|c|c|c|c|c|c|c|c}
\hline Aluno & \multicolumn{3}{|c|}{$\mathrm{J}$} & \multicolumn{3}{c|}{$\mathrm{K}$} & \multicolumn{3}{c}{$\mathrm{L}$} \\
\hline Critérios $^{1}$ & Inicial & $1^{\circ} \mathrm{B}^{2}$ & $2^{\circ} \mathrm{B}^{3}$ & Inicial & $1^{\circ} \mathrm{B}^{2}$ & $2^{\circ} \mathrm{B}^{3}$ & Inicial & $1^{\circ} \mathrm{B}^{2}$ & $2^{\circ} \mathrm{B}^{3}$ \\
\hline Proposições válidas e significativas & 6 & 17 & 26 & 6 & 32,5 & 30 & 6,5 & 22 & 34 \\
\hline Hierarquia: cada nível válido & 7,5 & 17,5 & 20 & 20 & 30 & 20 & 7,5 & 12,5 & 30 \\
\hline $\begin{array}{l}\text { Ligações transversais válidas e } \\
\text { significativas }\end{array}$ & 0 & 0 & 0 & 0 & 50 & 0 & 0 & 30 & 20 \\
\hline Ligações transversais válidas & 0 & 0 & 0 & 0 & 0 & 0 & 0 & 0 & 0 \\
\hline Ligações transversais criativas & 0 & 0 & 0 & 0 & 1 & 0 & 0 & 1 & 1 \\
\hline Exemplos válidos & 3 & 5 & 4 & 0 & 0 & 2 & 1 & 0 & 3 \\
\hline Total & 16,5 & 39,5 & 50 & 26 & 113,5 & 52 & 15 & 65,5 & 88 \\
\hline
\end{tabular}

${ }^{1}$ Critérios Classificatórios dos Mapas Conceituais utilizados por MARTINS et al. $2009 .{ }^{2} 1^{\circ}$ bimestre. ${ }^{3} 2^{\circ}$ bimestre.

Fonte: Elaboração própria. 
Tabela 3: Pontuação obtida após análise dos Mapas Conceituais construídos pelos alunos de M a W.

\begin{tabular}{l|c|c|c|c|c|c|c|c}
\hline \multicolumn{1}{c|}{ Aluno } & \multicolumn{3}{c|}{$\mathrm{M}$} & \multicolumn{3}{c|}{$\mathrm{N}$} & \multicolumn{3}{c}{$\mathrm{O}$} \\
\hline \multicolumn{1}{c|}{ Critérios $^{1}$} & Inicial & $1^{\circ} \mathrm{B}^{2}$ & $2^{\circ} \mathrm{B}^{3}$ & Inicial & $1^{\circ} \mathrm{B}^{2}$ & $2^{\circ} \mathrm{B}^{3}$ & Inicial & $1^{\circ} \mathrm{B}^{2}$ \\
\hline Proposições válidas e significativas & 13 & 25 & 31 & 10 & 16 & 28 & 6 & 10,5 \\
\hline Hierarquia: cada nível válido & 10 & 17,5 & 45 & 15 & 22,5 & 30 & 10 & 17,5 \\
\hline Ligações transversais válidas e significativas & 0 & 5 & 40 & 0 & 5 & 0 & 0 & 10 \\
\hline Ligações transversais válidas & 0 & 0 & 0 & 0 & 0 & 0 & 0 & 0 \\
\hline Ligações transversais criativas & 0 & 0,5 & 3 & 0 & 0 & 0 & 0 & 1 \\
\hline Exemplos válidos & 20 & 0 & 0 & 1 & 2 & 0 & 2 & 6 \\
\hline Total & 43 & 48 & 119 & 26 & 45,5 & 58 & 18 & 45 \\
\hline
\end{tabular}

\begin{tabular}{l|c|c|c|c|c|c|c|c|c}
\hline \multicolumn{1}{c|}{ Aluno } & \multicolumn{2}{c|}{$\mathrm{P}$} & \multicolumn{2}{c|}{$\mathrm{Q}$} & \multicolumn{2}{c|}{$\mathrm{R}$} & \multicolumn{2}{c}{$\mathrm{S}$} \\
\hline \multicolumn{1}{c|}{ Critérios $^{1}$} & Inicial & $1^{\circ} \mathrm{B}^{2}$ & Inicial & $1^{\circ} \mathrm{B}^{2}$ & Inicial & $2^{\circ} \mathrm{B}^{3}$ & Inicial & $1^{\circ} \mathrm{B}^{2}$ \\
\hline Proposições válidas e significativas & 11,5 & 15,5 & 4 & 10 & 6,5 & 19 & 8 & 12,5 \\
\hline Hierarquia: cada nível válido & 22,5 & 17,5 & 5 & 12,5 & 12,5 & 15 & 12,5 & 10 \\
\hline Ligações transversais válidas e significativas & 5 & 0 & 0 & 0,5 & 0 & 0 & 0 & 0 \\
\hline Ligações transversais válidas & 0 & 0 & 0 & 0 & 0 & 0 & 0 & 0 \\
\hline Ligações transversais criativas & 0,5 & 0 & 0 & 0 & 0 & 0 & 0 & 0 \\
\hline Exemplos válidos & 0 & 0 & 2 & 1 & 0 & 0 & 3 & 0 \\
\hline Total & 39,5 & 33 & 11 & 24 & 19 & 34 & 23,5 & 22,5 \\
\hline
\end{tabular}

\begin{tabular}{l|c|c|c|c|c|c|c|c|c}
\hline \multicolumn{1}{c|}{ Aluno } & \multicolumn{2}{c|}{$\mathrm{T}$} & \multicolumn{2}{c|}{$\mathrm{U}$} & \multicolumn{2}{c|}{$\mathrm{V}$} & \multicolumn{3}{c}{$\mathrm{W}$} \\
\hline \multicolumn{1}{c|}{ Critérios $^{1}$} & Inicial & $1^{\circ} \mathrm{B}^{2}$ & Inicial & $2^{\circ} \mathrm{B}^{3}$ & Inicial & $1^{\circ} \mathrm{B}^{2}$ & Inicial & $2^{\circ} \mathrm{B}^{3}$ \\
\hline Proposições válidas e significativas & 5,5 & 21 & 9 & 11 & 8 & 12,5 & 5,5 & 9,5 \\
\hline Hierarquia: cada nível válido & 10 & 30 & 15 & 12,5 & 10 & 20 & 7,5 & 10 \\
\hline Ligações transversais válidas e significativas & 0 & 10 & 20 & 0 & 0 & 0 & 0 & 0 \\
\hline Ligações transversais válidas & 0 & 0 & 0 & 0 & 0 & 0 & 0 & 0 \\
\hline Ligações transversais criativas & 0 & 1 & 0 & 0 & 0 & 1 & 0 & 0 \\
\hline Exemplos válidos & 0 & 0 & 0 & 0 & 1 & 0 & 0 & 2 \\
\hline Total & 15,5 & 62 & 44 & 23,5 & 19 & 33,5 & 13 & 21,5 \\
\hline
\end{tabular}

${ }^{1}$ Critérios Classificatórios dos Mapas Conceituais utilizados por MARTINS et al. 2009. ${ }^{2} 1^{\circ}$ bimestre. ${ }^{3} 2^{\circ}$ bimestre.

Fonte: Elaboração própria.

Analisando os dados apresentados nas Tabelas 2 e 3 é possível verificar uma evolução conceitual progressiva para a maior parte dos discentes participantes desta pesquisa (87\%). Dos 14 alunos que confeccionaram os três Mapas Conceituais, 8 (C, D, E, G, J, L, M e N) apresentaram uma evolução conceitual progressiva, tendo um aumento da pontuação do primeiro até o terceiro mapa elaborado. Para os dis- 
centes que produziram somente dois Mapas Conceituais foi observado que $6(\mathrm{O}, \mathrm{Q}$, $\mathrm{R}, \mathrm{T}, \mathrm{V}$ e W) dentre os 9 apresentaram aumento na pontuação do primeiro para o segundo mapa. Esses dados indicam uma reorganização construtiva na estrutura cognitiva desses discentes, o que permite sugerir, junto com uma análise estrutural qualitativa, uma contribuição para a aprendizagem significativa do discente. Esse resultado pode estar associado ao formato da disciplina que utilizou dois diferentes recursos, a saber a experimentação descritiva e os Mapas Conceituais para potencializar o processo de ensino e aprendizagem. Além disso, por meio deste trabalho é percebido que a introdução de novas estratégias educacionais motiva os discentes, facilitando ainda mais a aprendizagem, permitindo o desenvolvimento de diferentes competências e habilidades no educando (MARTINS et al., 2009a).

Os resultados obtidos pelos Mapas Conceituais nos três momentos foram categorizados em seis faixas distintas, assim como apresentado na metodologia desse trabalho. Essas faixas serviram de orientação para conferir conceitos aos mapas elaborados pelos discentes. A porcentagem de mapas em cada uma das faixas e em cada momento é apresentada na Figura 3, sendo perceptível que ao final dos bimestres os discentes confeccionaram Mapas Conceituais mais elaborados, com destaque para o $2^{\circ}$ bimestre, em que $53 \%$ dos Mapas Conceituais foram considerados acima do esperado.

Figura 3: Faixas de pontuação obtidas pelos Mapas Conceituais dos discentes nos três momentos de estudo dessa pesquisa (sendo, $1^{\circ} \mathrm{B}-1^{\circ}$ bimestre e $2^{\circ} \mathrm{B}-2^{\circ}$ bimestre).

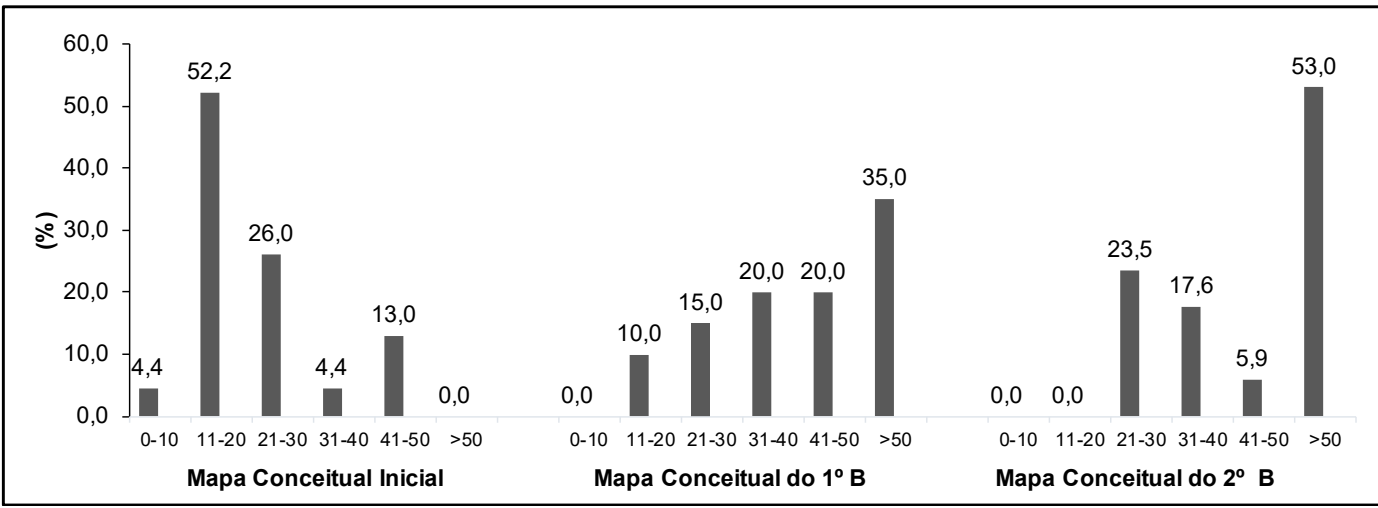

Fonte: Elaboração própria. 
Apesar de alguns alunos que realizaram os três Mapas Conceituais não apresentarem um aumento progressivo nas pontuações obtidas, eles elaboraram mapas ricos em detalhes, principalmente ao fim de cada etapa. Dentre esses é possível citar o aluno A, que apresentou um primeiro Mapa Conceitual com elevada riqueza de conceitos e proposições válidas, além de um elevado nível hierárquico (Tabela 2). Os mapas elaborados ao final de cada um dos dois bimestres apresentaram evolução nesses critérios quando comparados com o primeiro mapa. No entanto, esses dois parâmetros permaneceram praticamente inalterados quando os mapas finais foram analisados de forma comparativa. Esses dados indicam que o referido aluno apresentou uma evolução conceitual mais pronunciada na primeira parte da disciplina, ou não demonstrou toda sua potencialidade na confecção do último Mapa Conceitual. Outro aspecto que merece ser evidenciado é a não observação de nenhuma ligação transversal no último mapa elaborado pelo discente, contrapondo as três observadas no Mapa Conceitual confeccionado ao final do primeiro bimestre (Figura 4), acarretando assim, na diminuição da pontuação obtida pelo educando.

As ligações transversais válidas e significativas apresentadas no Mapa Conceitual obtido ao final do primeiro bimestre pelo aluno A estão apresentadas em vermelho na Figura 4, sendo uma delas criada entre a relação válida do processo de sedimentação da matéria orgânica e a rocha reservatório. Já a segunda está associada a interrelação entre a quantidade de asfaltenos e o preço do petróleo, além de demonstrar a influência dessa classe de compostos químicos na densidade desse fluido. A terceira ligação transversal encontra-se em azul na Figura 4, sendo essa considerada apenas válida, visto que não foi considerado significativo para um aluno do módulo IV de um Curso Técnico em Química, destacar que a água interage com o sal. Neste caso, era requerido do discente que indicasse os motivos que permitem essa interação. Ademais, o referido aluno utilizou palavras-chave em todas as ligações entre conceitos na confecção dos três Mapas Conceituais. 
Figura 4: Mapa Conceitual do aluno A referente ao primeiro bimestre (Fonte: Elaboração própria).

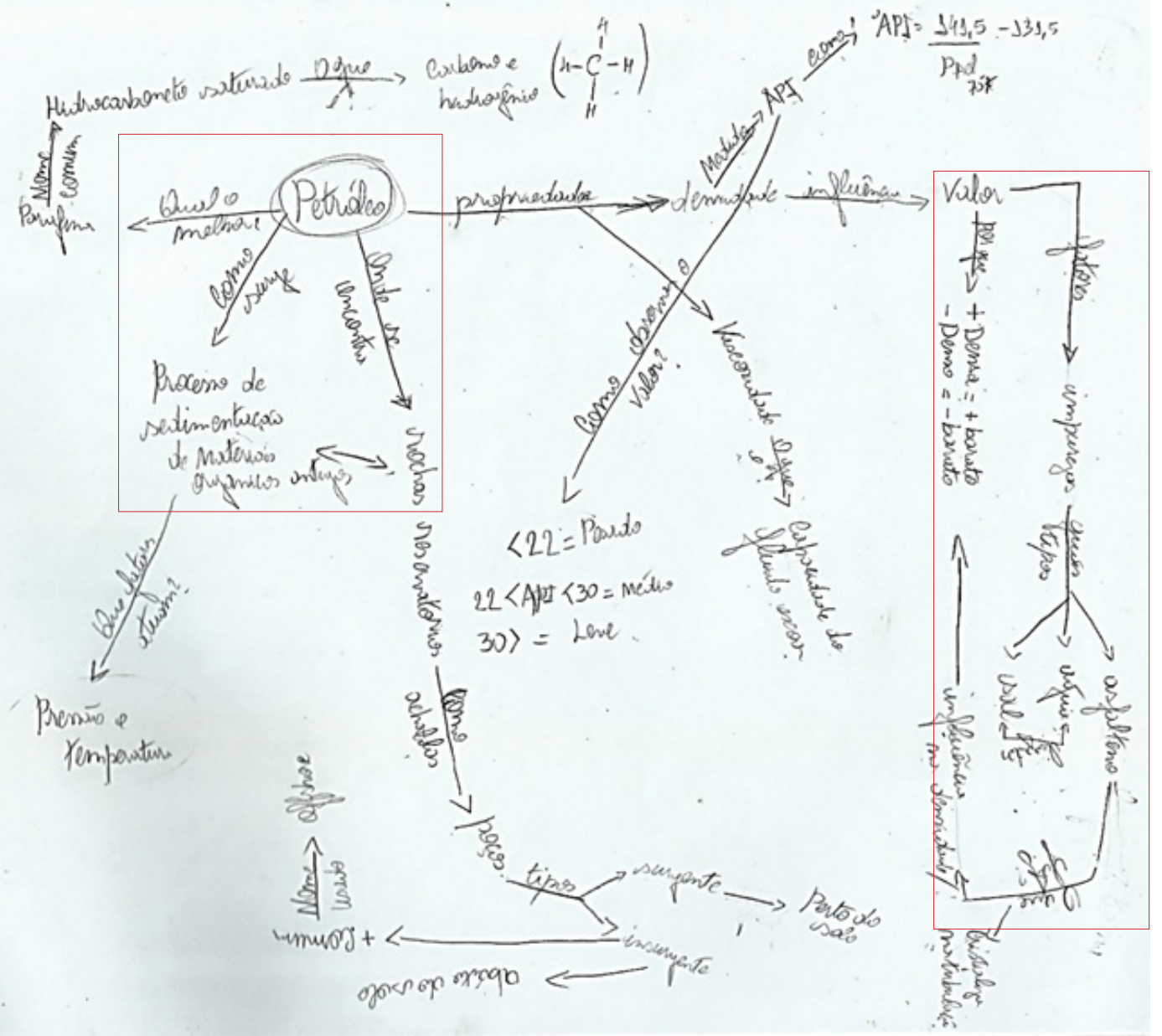

Outro discente que merece destaque é o aluno $\mathrm{D}$, que apresentou um primeiro Mapa Conceitual relativamente pobre, mas com ligações entre conceitos providas de palavras de enlace. No segundo mapa, o número de conceitos utilizados pelo aluno aumentou, entretanto, todos estavam desprovidos das referidas palavras. O último Mapa Conceitual (Figura 5) apresentou-se mais rico que o do primeiro bimestre, compreendendo alguns novos conceitos, os quais, em sua maioria, apresentaram palavras de ligação. Também se observou um aumento progressivo de proposições válidas do primeiro ao último mapa, todavia, esse aumento foi pequeno. 
Figura 5: Mapa Conceitual do aluno D referente ao segundo bimestre (Fonte: Elaboração própria).

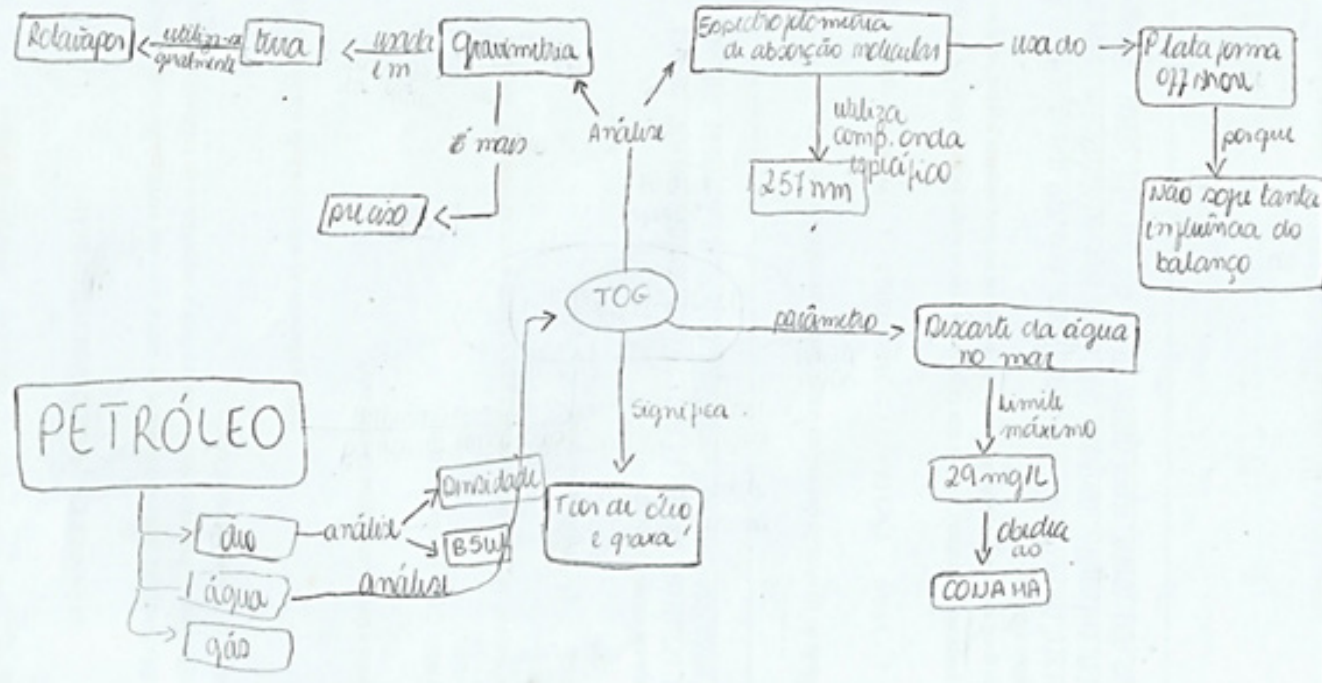

No Mapa Conceitual referente ao segundo bimestre (Figura 5) a maioria das proposições representadas pelo aluno D eram referentes aos conteúdos trabalhados nessa mesma época. Sendo assim o discente acabou focando mais nos conceitos relacionados ao TOG (Teor de Óleos e Graxas) do que nos conceitos relacionados às análises físico-químicas do petróleo. Todavia, duas análises que estavam presentes na primeira parte da disciplina foram citadas, sendo estas: densidade e $B S W$ (Basic Sediments and Water), demonstrando que esses conceitos permaneceram por mais tempo na estrutura cognitiva desse educando.

Assim como o aluno D, o estudante $\mathrm{E}$ apresentou, com maior riqueza de detalhes, conteúdos trabalhados na segunda parte da disciplina ao invés de utilizar o tema petróleo como principal, fazendo com que um dos conteúdos do segundo bimestre fosse colocado como central na confecção do seu último Mapa Conceitual. Neste caso, o conceito abordado foi "Fluido de Perfuração", sendo o tema "Petróleo" sequer citado. $\mathrm{O}$ aluno em questão apresentou uma evolução conceitual significativa ao longo do semestre, fazendo uso de palavras-chave na grande maioria das ligações entre conceitos. A análise comparativa entre os três mapas destacou um aumento no número de níveis hierárquicos do segundo para o terceiro mapa, todavia, esse aumento foi pequeno. Ademais, o discente apresentou duas ligações transversais válidas e significativas, estando uma delas presente no segundo Mapa Conceitual 
(Figura 6) e a outra no terceiro (Figura 7). Em ambos os casos as ligações transversais são destacadas em vermelho nos seus respectivos Mapas Conceituais, as quais merecem lugar de destaque devido a sua importância no processo de realização da reconciliação integrativa, sendo esse o motivo pelo qual Martins e colaboradores (2009a) gratificam de forma mais expressiva esse tipo de ligação.

Com relação às ligações transversais válidas e significativas apresentadas pelo aluno E, foi verificado que a ligação presente no segundo Mapa Conceitual (Figura 6), assim como para o aluno A, estava relacionada ao preço do petróleo. No entanto, esse discente destacou a influência da presença da água como contaminante, levando à uma diminuição do valor agregado do petróleo, enquanto que o aluno $\mathrm{A}$ destacou os asfaltenos como contaminantes (Figura 4). No terceiro Mapa Conceitual (Figura 7) o aluno E destacou uma ligação transversal válida e significativa entre os fluidos de perfuração e os adensantes, de tal modo que fosse possível relacionar o controle da pressão hidrostática, presente nos poços em processo de perfuração, com a adição de agentes adensantes, sendo esse controle uma das principais funções dos fluidos de perfuração.

Figura 6: Mapa Conceitual do aluno E referente ao primeiro bimestre (Fonte: Elaboração própria).

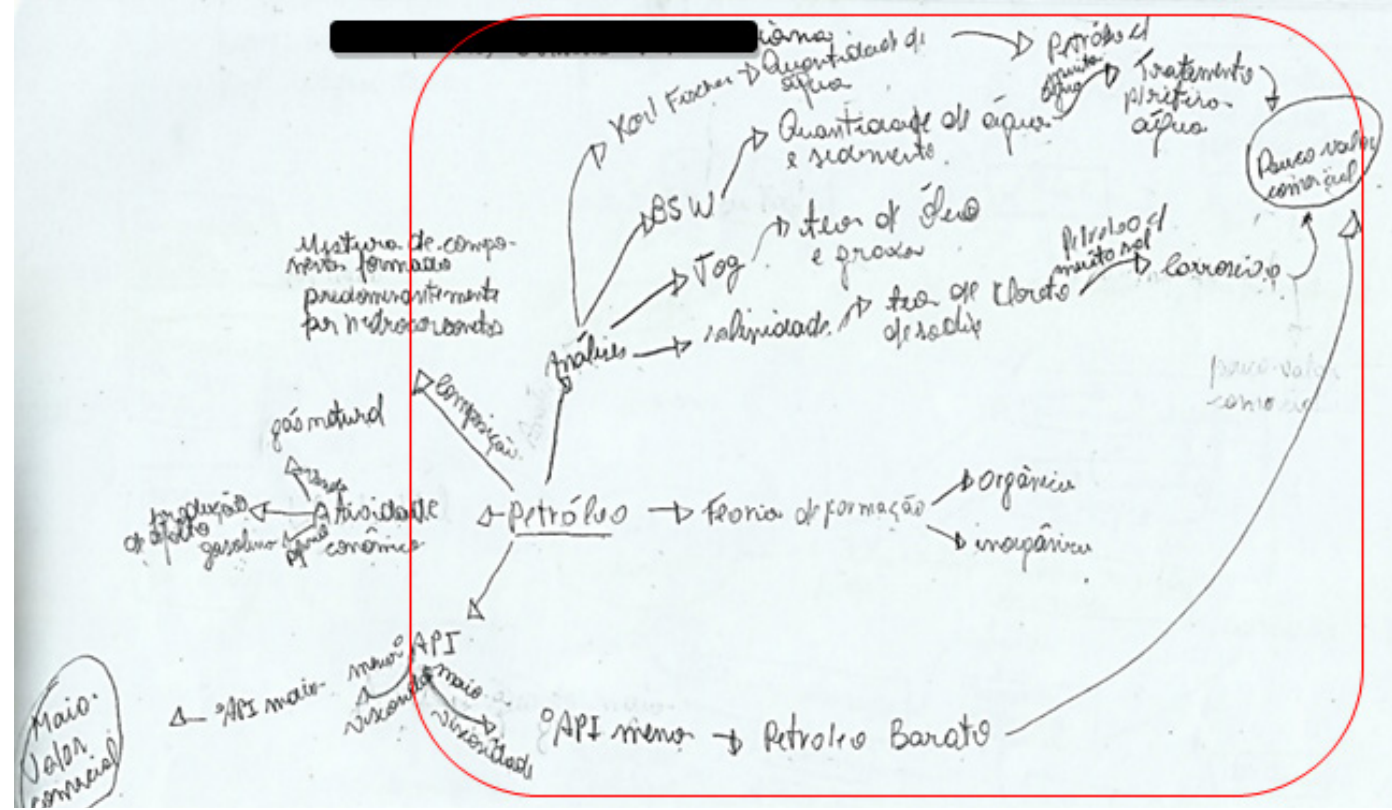


Figura 7: Mapa Conceitual do aluno E referente ao segundo bimestre (Fonte: Elaboração própria).

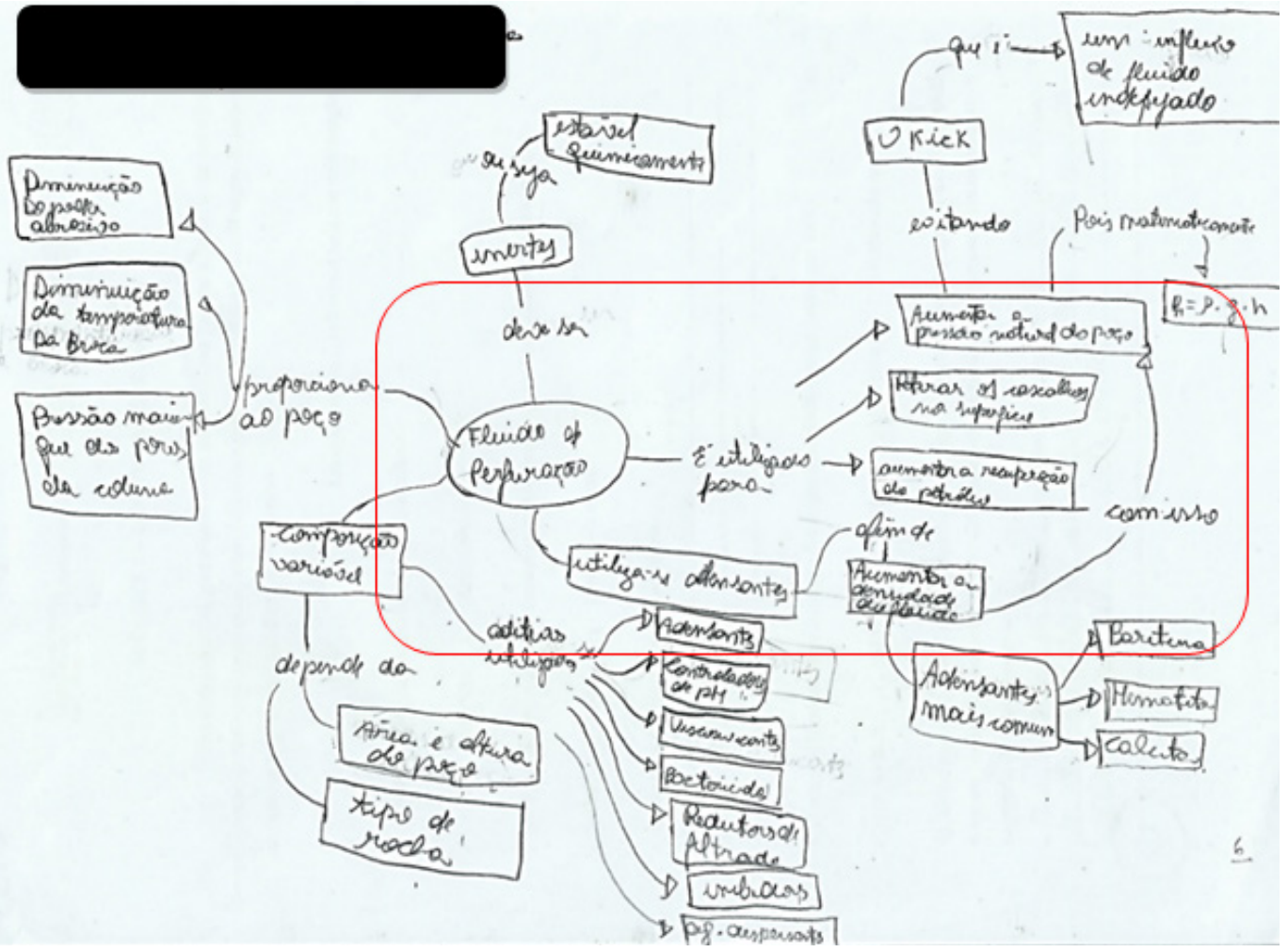

Os dados obtidos pela análise dos Mapas Conceituais do aluno $\mathrm{H}$ também merecem destaque, visto que esses indicam a presença de uma evolução conceitual significativa no que se refere às proposições e níveis hierárquicos do primeiro para o segundo Mapa Conceitual. Todavia, observou-se uma evolução conceitual pequena em relação a esses dois quesitos quando parte-se do segundo para o terceiro mapa. O aprendiz apresentou uma ligação transversal no segundo mapa (Figura 8), a qual foi considerada válida, significativa e criativa. A referida ligação não se repetiu no último Mapa Conceitual (Figura 9), todavia, ambos os mapas apresentaram a mesma pontuação total, visto que o nível hierárquico e o número de proposições válidas, apresentados no terceiro mapa, foram superiores, o que suprimiu a pontuação apresentada pela ligação transversal presente no segundo mapa. 
Figura 8: Mapa Conceitual do aluno H referente ao primeiro bimestre (Fonte: Elaboração própria).

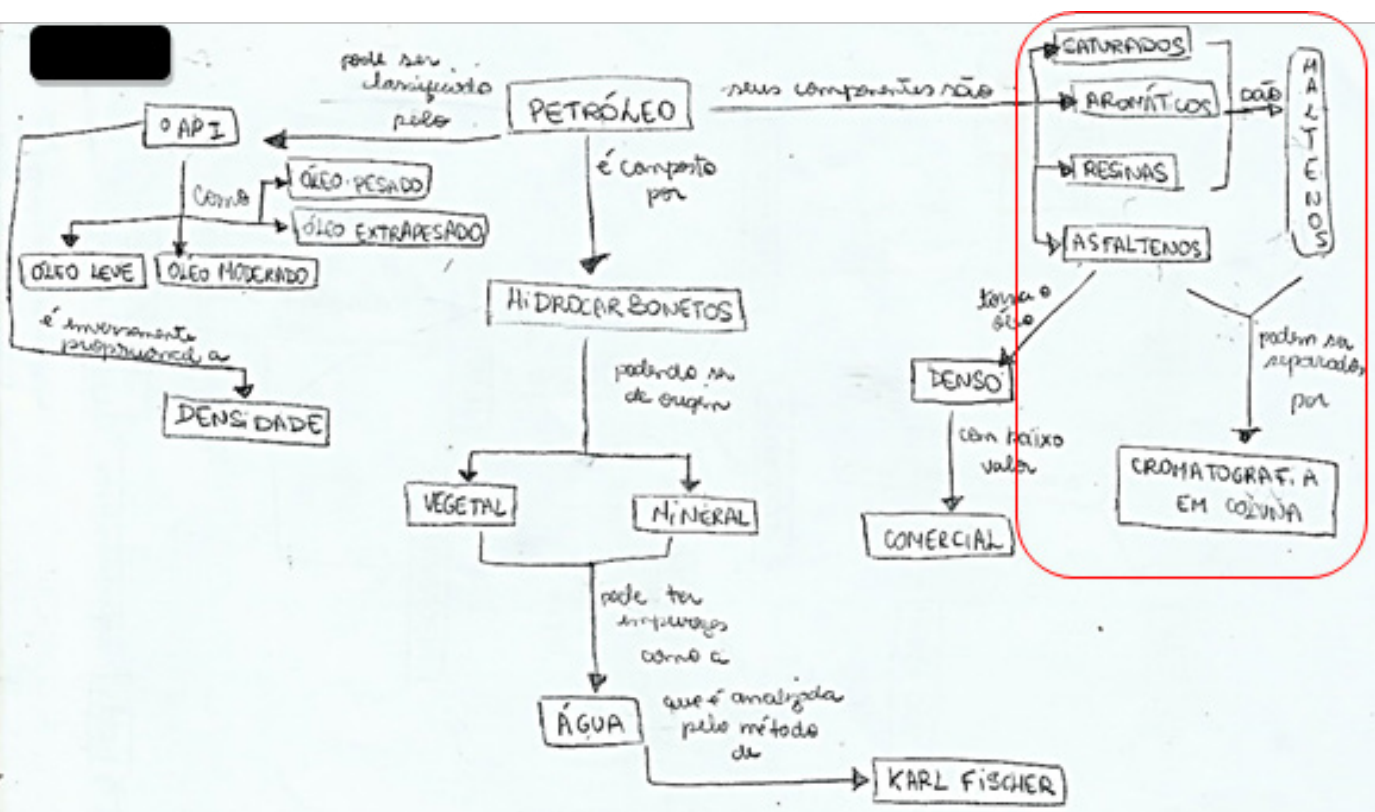

Figura 9: Mapa Conceitual do aluno H referente ao segundo bimestre (Fonte: Elaboração própria).

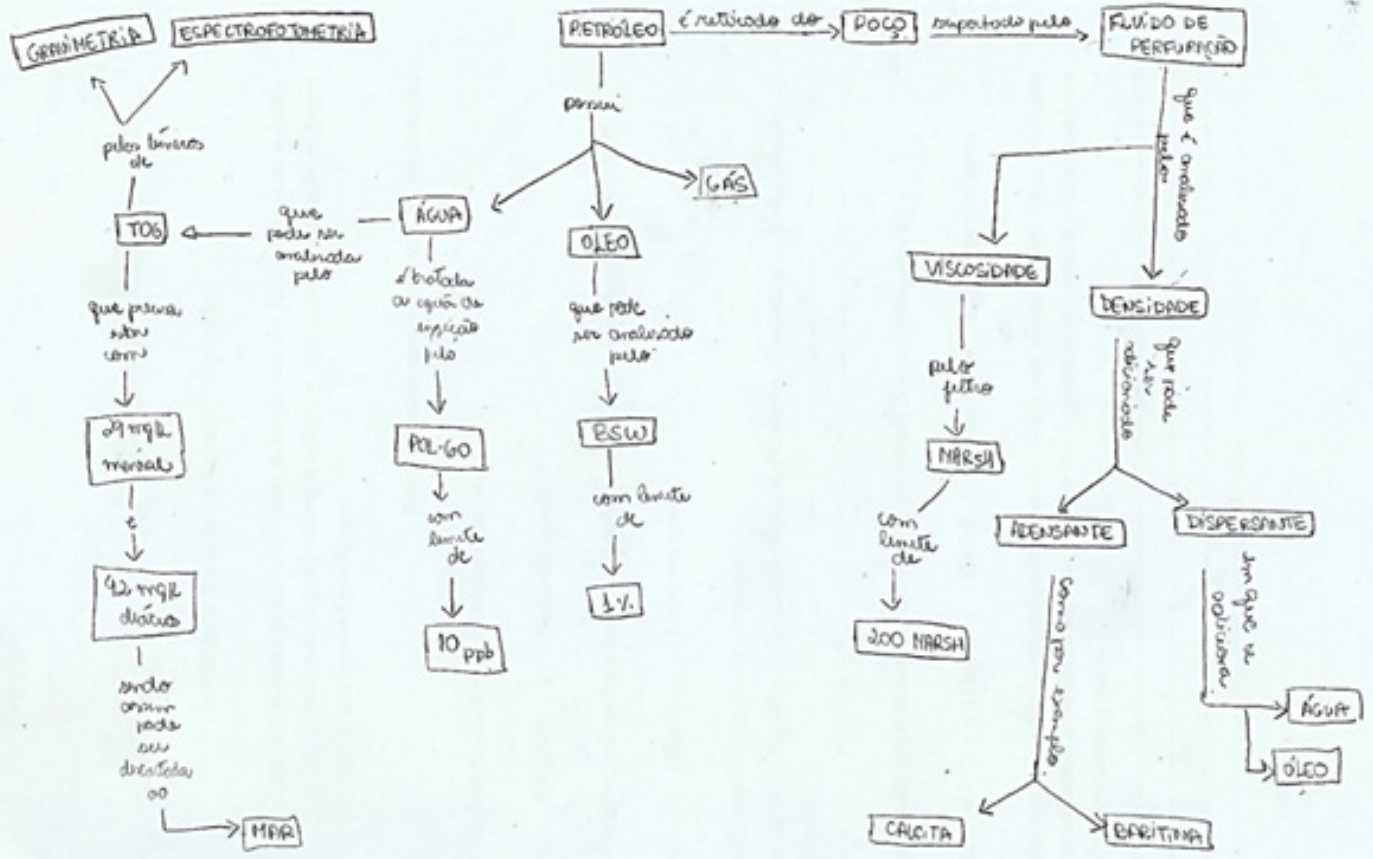


A ligação transversal válida e significativa elaborada pelo aluno $\mathrm{H}$, representada em vermelho na Figura 8, foi considerada criativa, pois os conceitos presentes nessa proposição foram relacionados a um conteúdo de outra disciplina do módulo IV do curso Técnico em Química, a saber, Cromatografia. O discente conseguiu identificar as diferenças de polaridade existentes entre os componentes do petróleo, destacando a cromatografia em coluna como sendo uma técnica que possibilita a separação desses em diferentes frações.

$\mathrm{O}$ aluno $\mathrm{K}$ apresentou uma evolução conceitual muito significativa do primeiro (Figura 10) para o segundo (Figura 11) mapa, que se mostrou muito rico em proposições válidas, níveis hierárquicos e ligações transversais, porém foram observadas poucas palavras de ligação. Vale ressaltar que esse discente faltou ao primeiro encontro, quando foi discutida uma introdução ao conteúdo, desta forma, seu primeiro Mapa Conceitual apresentou conceitos não somente relacionados com a Química, mas também ao cenário geopolítico que envolve o tema. Dentro desse cenário, o referido aluno destacou o petróleo como sendo fonte de renda para os países produtores, gerando recursos financeiros que acentua o sistema capitalista, o que muitas das vezes, pode gerar disputas, principalmente no Oriente Médio. Além disso, o referido aluno apresentou em seu Mapa Conceitual uma crítica ao sistema capitalista, destacando que o mesmo se baseia numa exploração contínua, que se não for analisada com cautela poderá causar graves desastres ambientais (Figura 10). 
Figura 10: Mapa Conceitual inicial do aluno K (Fonte: Elaboração própria).

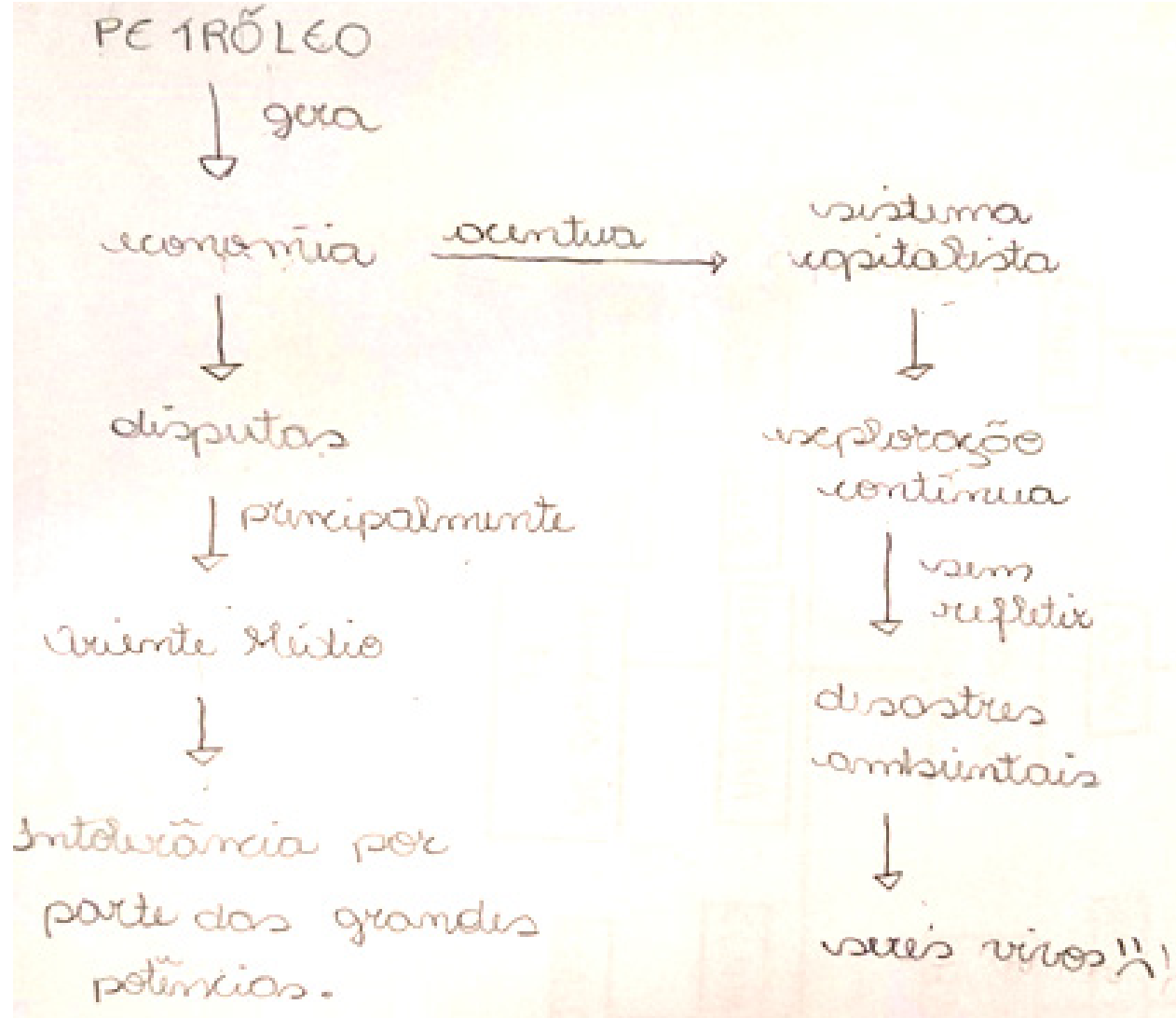

Diferentemente do que foi observado no primeiro Mapa Conceitual, o aluno K apresentou em seu segundo mapa (Figura 11) um embasamento químico sólido, contendo várias proposições válidas, algumas com e outras sem palavras de ligação. No entanto, o que mais se destaca no referido mapa são as cinco ligações transversais válidas e significativas, as quais podem ser observadas em vermelho na Figura 11. A primeira ligação transversal indica que dois dos principais grupos de compostos presentes no petróleo são classificados como hidrocarbonetos, sendo um deles nomeado de "aromáticos" e o outro de "saturados". As demais frações (Resinas e Asfaltenos) são consideradas não hidrocarbonetos, sendo assim, apresentam grupos funcionais orgânicos em suas estruturas, o que proporciona uma interação entre as substâncias presentes nessas duas classes de compostos, resultando na estabilização das partículas asfaltênicas no interior do petróleo, o que pode ser observado em uma 
segunda ligação transversal. O referido mapa do discente também apresentou uma ligação transversal entre dois contaminantes presentes no petróleo $\left(\mathrm{H}_{2} \mathrm{O}\right.$ e $\left.\mathrm{H}_{2} \mathrm{~S}\right)$ e os processos de corrosão presentes na indústria petrolífera. Por fim, as outras duas ligações transversais estão relacionadas às propriedades do petróleo (densidade e viscosidade), em que uma delas apresentou a correlação entre estas variáveis por meio de expressões matemáticas em uma ligação transversal específica, sendo essa considerada criativa.

Figura 11: Mapa Conceitual do aluno K referente ao primeiro bimestre (Fonte: Elaboração própria).

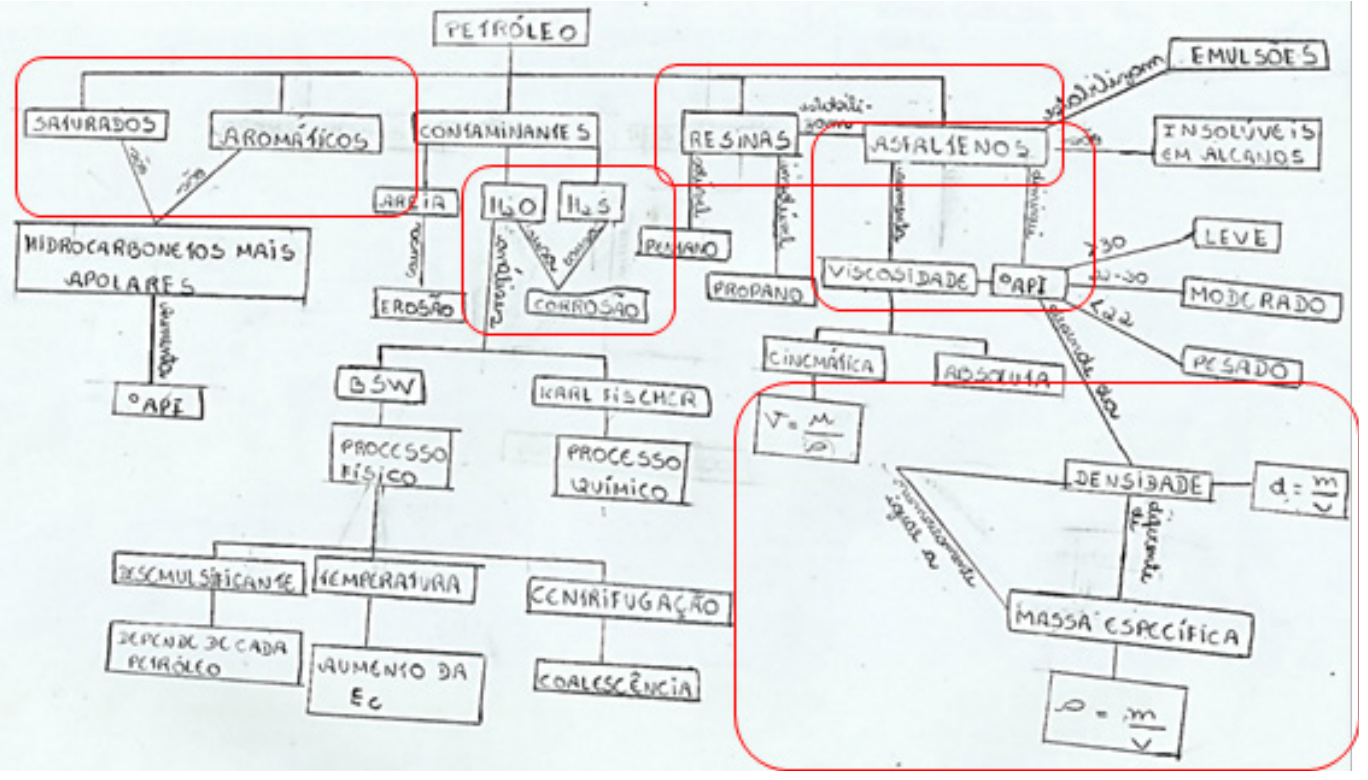

Por fim, cabe destacar os Mapas Conceituais apresentados pelo aluno L. Dentre todas as seis ligações transversais válidas e significativas, apresentadas por esse aluno em seu segundo Mapa Conceitual, somente uma não foi apresentada pelos demais discentes, as outras também foram relatadas pelos alunos $\mathrm{A}, \mathrm{Ke} \mathrm{H}$, as quais foram discutidas anteriormente e são destacadas em vermelho na Figura 12. A única que não foi apresentada por nenhum outro discente diz respeito à formação de emulsões por meio do contato entre a água e o óleo, sendo esses fluidos produzidos pela indústria petrolífera. Cabe ressaltar que o referido discente não apresentou palavras de ligação entre as proposições presentes nas ligações transversais, o que reduziu pela metade os valores acrescidos para esses tipos de ligações. 
Figura 12: Mapa Conceitual do aluno L referente ao primeiro bimestre (Fonte: Elaboração própria).

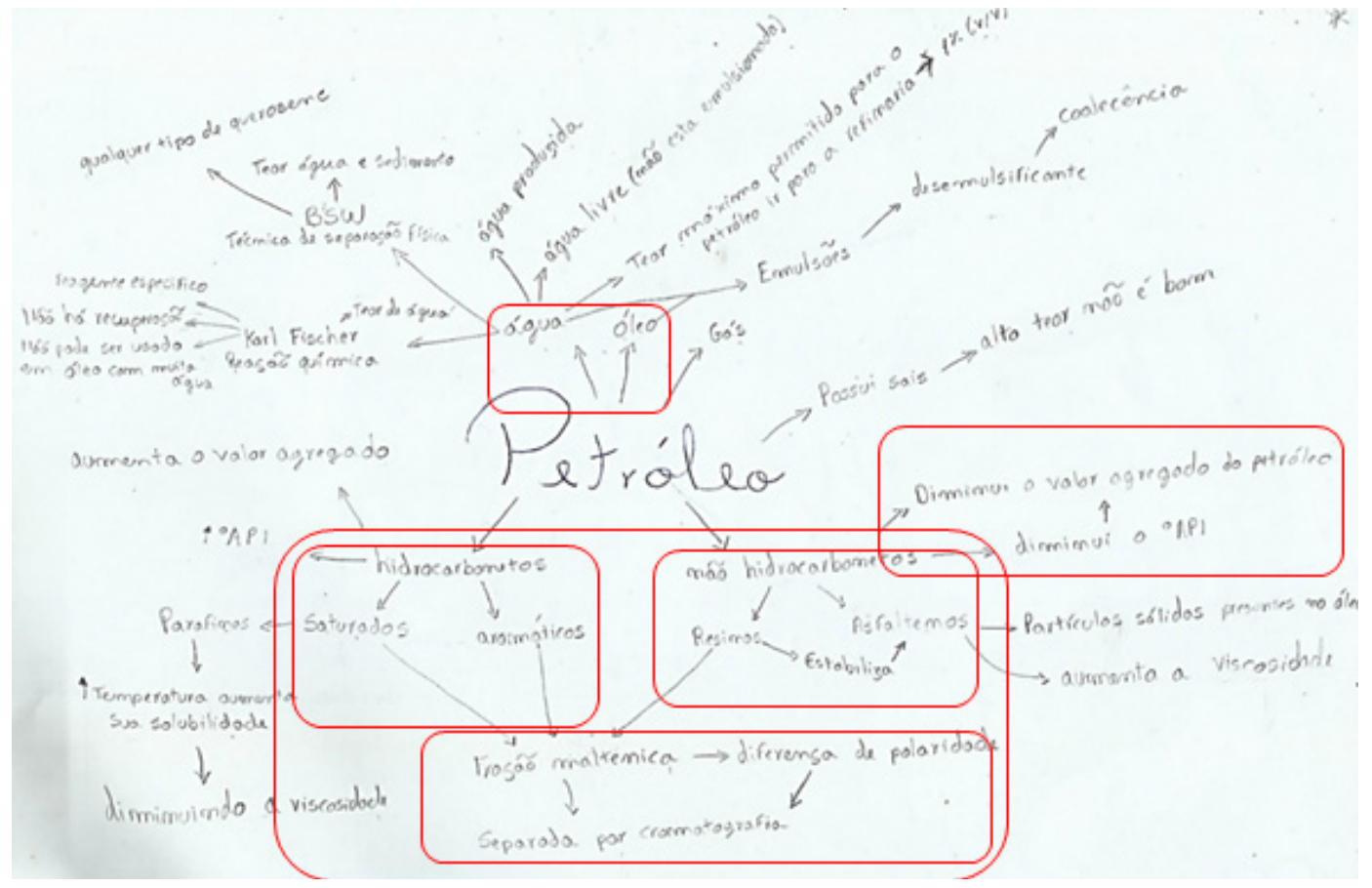

Mesmo apresentando um Mapa Conceitual bem completo ao final do primeiro bimestre, o aluno L conseguiu apresentar uma evolução conceitual ainda maior ao final do segundo bimestre (Figura 13). Isso foi devido ao aumento no número de proposições válidas e significativas e também ao aumento no nível hierárquico apresentado do segundo para o último Mapa Conceitual do referido discente. No entanto, observou-se uma redução na quantidade de ligações transversais válidas e significativas, porém essas foram consideradas por completo, visto que neste mapa o discente utilizou as palavras de ligação para conectar os conceitos. Neste mapa foram observadas duas ligações transversais, sendo uma exatamente igual a apresentada no segundo Mapa Conceitual do discente e a outra relacionada a um dos conteúdos da segunda parte da disciplina, a saber Fluidos de Perfuração, de forma similar ao realizado pelo aluno E. 
Figura 13: Mapa Conceitual do aluno L referente ao segundo bimestre

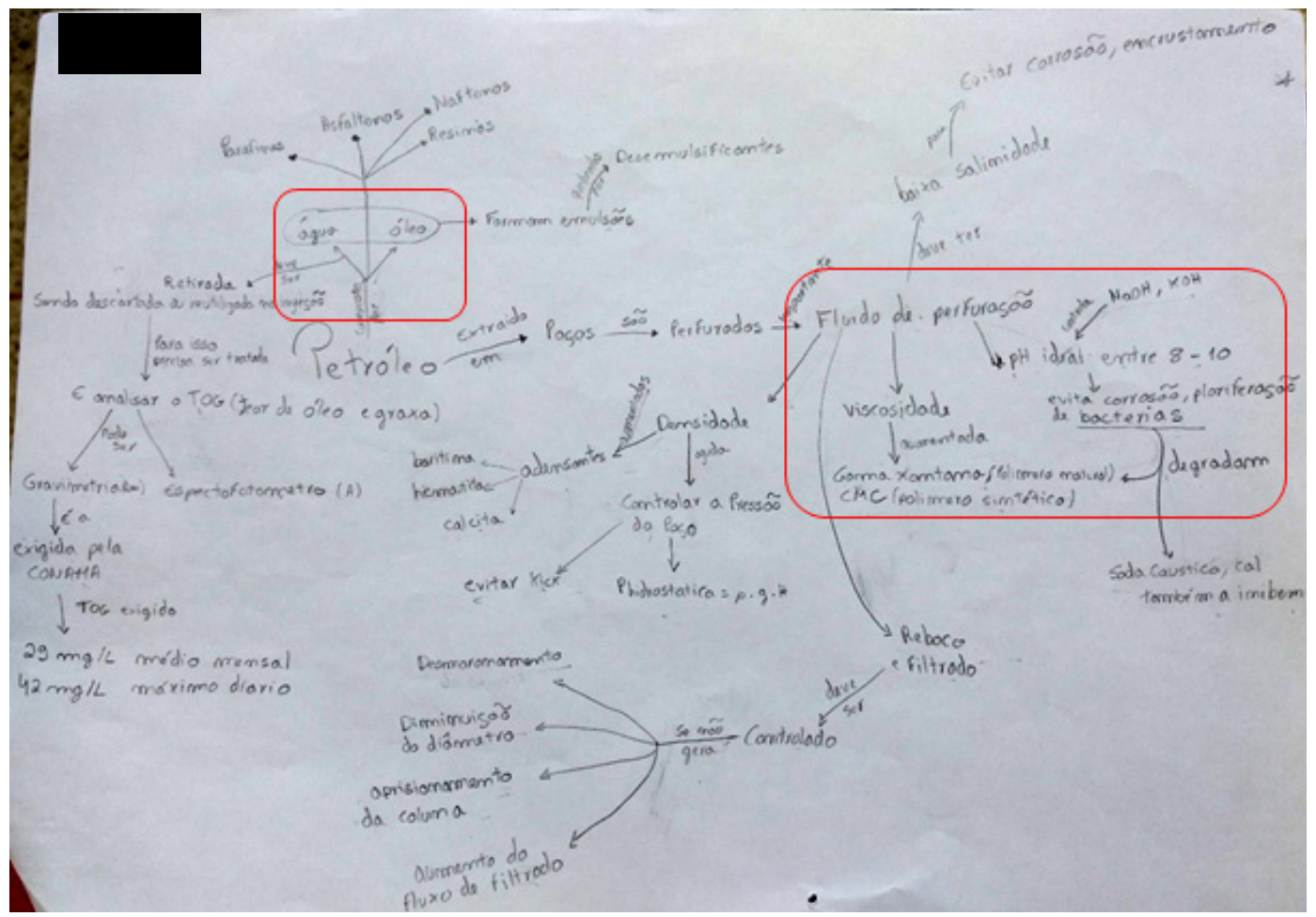

Fonte: Elaboração própria

Baseando-se nos Mapas Conceituais elaborados pelos discentes é possível verificar que esse recurso se mostra bastante interessante como ferramenta de avaliação, mesmo para cursos marcados por modelos tecnicistas de ensino, como os cursos profissionalizantes de nível médio. Sendo assim, os dados coletados neste trabalho estão de acordo com Struchiner e colaboradores (1999), que relatam que o uso de Mapas Conceituais é uma forma muito eficiente de avaliar o conhecimento estrutural do discente, os quais descrevem visualmente as correlações entre as ideias do educando a respeito de um determinado conhecimento, representando assim, sua estrutura cognitiva e as mudanças ocorridas nelas. Desta forma, a análise dos Mapas Conceituais elaborados pelos discentes, mediante a observação dos elementos constituintes da teoria da aprendizagem significativa de Ausubel, possibilitou a detecção de conhecimentos apresentados pelos alunos em diversos aspectos relevantes à sua formação científica e profissional. 
Apesar do potencial apresentado por essa ferramenta educacional uma parcela considerável dos educandos (56\%) apresentou dificuldade na confecção dos seus Mapas Conceituais, o que pode ser observado no gráfico da Figura 14. Esse resultado foi obtido por meio da análise das respostas do público alvo desta pesquisa para a Questão 3 do Questionário de Opinião. Sendo verificado que 35\% dos discentes alegaram achar "fácil" elaborar esse tipo de mapa, 39\% alegaram certo grau de dificuldade, $17 \%$ consideraram "muito difícil" e $9 \%$ dos respondentes preferiram não opinar.

Figura 14: Respostas dos alunos à Questão 3 do Questionário de Opinião.

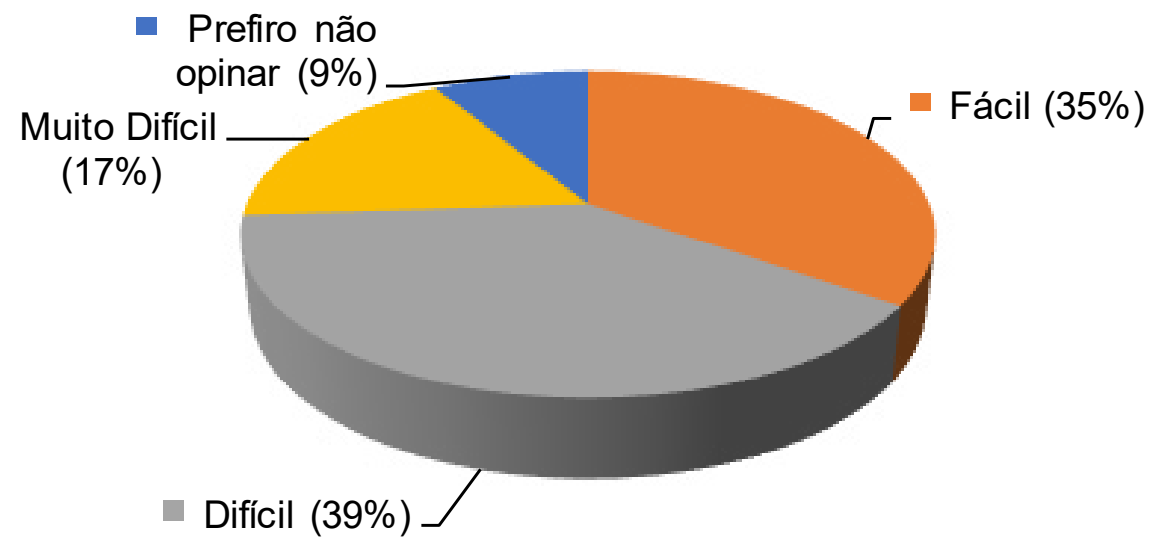

(Fonte: Elaboração própria).

Apesar de grande parte dos alunos terem destacado que conhecia os Mapas Conceituais, durante a aplicação deste projeto foi perceptível a falta de familiaridade da maior parte dos discentes no processo de construção dessa ferramenta de ensino. A falta de habilidade na confecção dos mapas possivelmente é devido a sua pouca utilização como recurso educacional, o que está de acordo com Pivatto (2013). O referido autor aponta que embora os Mapas Conceituais sejam instrumentos adequados para utilização em sala de aula ou em laboratório, poucos professores fazem uso desse instrumento, o que consequentemente resulta na falta de experiência dos educandos no momento de expressar sua complexa rede de conhecimentos em apenas um único mapa. Alguns alunos inclusive destacaram que tinham muitas informações e conceitos para serem expressos em apenas uma única folha, o que sugere um aumento substancial na estrutura cognitiva dos discentes a respeito dos conteúdos ministrados pela disciplina. Portanto, a falta de contato habitual com os 
Mapas Conceituais pode refletir a dificuldade que os alunos apresentaram no processo de elaboração dos seus próprios mapas. Deste modo, ressalta-se a importância de ambientar os discentes no processo de construção dos Mapas Conceituais, para que eles saibam fazer uso adequado dessa ferramenta em seu cotidiano escolar.

Por fim, ao final do projeto, ao responder à Questão 4 do Questionário de Opinião, os alunos foram convidados a relatar como foi a experiência com o projeto, ressaltando pontos positivos, negativos e oferecendo sugestões. As respostas apresentadas pelos discentes podem ser observadas no Quadro 4.

De forma geral, como ponto positivo os alunos relataram que os Mapas Conceituais que compunham seu material didático ajudaram a organizar os principais conceitos presentes na matéria, de forma simplificada e resumida, o que os ajudou a acompanhar melhor o conteúdo e entender a prática. Relataram também que foi uma ferramenta muito útil para estudar para as avaliações somativas e fazer uma revisão mais objetiva dos principais conteúdos. É relevante ressaltar o relato do aluno $\mathrm{T}$, o qual destaca que utilizar os mapas em conjunto com a aula auxiliou a acompanhar e entender o conteúdo. Isso se justifica, pois os Mapas Conceituais não são autoexplicativos (MOREIRA, 2011; 2012). Portanto, ao fazer uso do mapa em conjunto na aula, o professor está estimulando o potencial significativo dessa ferramenta pedagógica.

Outro relato que merece ser destacado foi apresentado pelo aluno V "Os mapas deste projeto se mostraram muito úteis na hora de revisar o conteúdo e até entender os procedimentos e objetivos da etapa experimental. Os Mapas Conceituais tendem a ser mais efetivos no meu caso por causa dos fluxogramas de fácil assimilação". Neste relato o discente destaca que a ferramenta utilizada foi bastante útil para eles, visto que ele considerou os fluxogramas apresentados de fácil assimilação. Portanto para o discente os mapas alcançaram seus objetivos.

Como ponto negativo alguns alunos relataram dificuldade em construir os seus próprios Mapas Conceituais. Esses relatos reiteram a importância de ambientar os discentes aos processos de construção e finalidades dos Mapas Conceituais. Além desses, o comentário do aluno U também merece ser evidenciado, "acho que o mapa conceitual apenas ajuda a decorar conceitos, e não a entender". O relato desse aluno está em desacordo com os demais discentes, porém esse comentário vai de encontro com a teoria de David Ausubel. Segundo esse autor se o aprendiz deseja aprender de forma não substancial e arbitrária, dificilmente a Aprendizagem Significativa será al- 
cançada, resultando em uma aprendizagem mecânica com maior potencialidade de ser esquecida, portanto o educando tem papel central em seu processo de aprendizagem.

Quadro 4: Justificativas apresentadas por alguns discentes para a questão número 4 do Questionário de Opinião.

\begin{tabular}{|c|c|}
\hline Aluno $^{1}$ & Justificativa \\
\hline A & $\begin{array}{l}\text { "Particularmente, eu gostei da experiência, pois ela é prática e dinâmica, além de objetiva, } \\
\text { fazendo o tempo ser melhor usado." }\end{array}$ \\
\hline B & "Os mapas conceituais são muito bons e bem resumidos, ótima ferramenta para o estudo." \\
\hline C & $\begin{array}{l}\text { Esse projeto me ajudou a organizar os pontos para serem estudados, assim, a linha de } \\
\text { raciocínio fica mais fácil. }\end{array}$ \\
\hline D & $\begin{array}{l}\text { Gostei. Na minha opinião são "resumos" bem rápidos que ajudam nos estudos. No entanto, } \\
\text { confesso que tenho dificuldade em criar mapas, quando eu dou conta copiei quase tudo do } \\
\text { que era pra resumir. }\end{array}$ \\
\hline $\mathrm{E}$ & $\begin{array}{l}\text { "A iniciativa foi boa, porém, a falta de tempo decorrido de muitas provas fez com que não } \\
\text { tivesse total aproveitamento do conteúdo. Entretanto, gostei." }\end{array}$ \\
\hline $\mathrm{F}$ & $\begin{array}{l}\text { "De acordo com os questionários que recebemos, facilita o entendimento e o estudo, porém } \\
\text { para nós mesmos elaborarmos, deveríamos ter mais tempo para o desenvolvimento. Na } \\
\text { hora de fazer o mapa faltou informações. Mas é uma ferramenta bem estruturada." }\end{array}$ \\
\hline G & "Eu gostei do trabalho feito, foi bem desenvolvido e prático." \\
\hline $\mathrm{H}$ & "Gostei, pois ajudou muito na hora de estudar para a prova." \\
\hline I & $\begin{array}{l}\text { Os mapas são bem produtíveis, eles ajudam muito nos estudos pois trazem uma linguagem } \\
\text { simples e de maneira resumida, de forma que facilita na hora de estudar para a prova. }\end{array}$ \\
\hline $\mathrm{J}$ & "Foi interessante a experiência pois é uma ferramenta de estudo útil e que ajuda muito." \\
\hline K & $\begin{array}{l}\text { Os mapas conceituais ajudaram a relacionar conceitos importantes da disciplina. Eles ajuda- } \\
\text { ram na obtenção de conhecimentos. }\end{array}$ \\
\hline $\mathrm{L}$ & "Gostei, facilita nos estudos e ajuda a entender o conteúdo." \\
\hline M & $-{ }^{2}{ }^{2}$ \\
\hline $\mathrm{N}$ & $\begin{array}{l}\text { "A ideia foi boa, ajuda, não tenho nada contra, mas por eu ter focado mais em entender, } \\
\text { estudar a matéria, acabei dando pouca prioridade ao mapa." }\end{array}$ \\
\hline $\mathrm{O}$ & $\begin{array}{l}\text { "Bom, os mapas conceituais só obtiveram pontos positivos. Foi de extrema ajuda nos estu- } \\
\text { dos, me permitiu entender melhor e também esclarecer algumas dúvidas." }\end{array}$ \\
\hline Q & $--^{2}+100$ \\
\hline $\mathrm{R}$ & "Sim gostei, pela facilidade no entendimento do tópico estudado." \\
\hline $\mathrm{T}$ & $\begin{array}{l}\text { Inicialmente parecia algo que não faria diferença, mas com uma melhor visualização do } \\
\text { mapa em conjunto com a aula, tornou-se uma ferramenta bastante útil para acompanhar e } \\
\text { entender todo o conteúdo. }\end{array}$ \\
\hline $\mathrm{U}$ & "Acho que o mapa conceitual apenas ajuda a decorar conceitos, e não a entender." \\
\hline V & $\begin{array}{l}\text { "Os mapas deste projeto se mostraram muito úteis na hora de revisar o conteúdo e até en- } \\
\text { tender os procedimentos e objetivos da etapa experimental. Os Mapas Conceituais tendem } \\
\text { a ser mais efetivos no meu caso por causa dos fluxogramas de fácil assimilação." }\end{array}$ \\
\hline W & $\begin{array}{l}\text { "Gostei, achei interessante e ótimo para se fazer a revisão dos conteúdos abordados em } \\
\text { sala de aula ao final das práticas." }\end{array}$ \\
\hline
\end{tabular}

Notas: ${ }^{1}$ Os alunos $\mathrm{S}$ e $\mathrm{P}$ não realizam o Questionário de Opinião pois evadiram no $2^{\circ}$ bimestre do curso. ${ }^{2}$ Os alunos $\mathrm{M}$ e $\mathrm{Q}$ não apresentaram a justificativa, apesar de terem respondido o Questionário de Opinião.

Fonte: Elaboração própria. 


\section{Conclusões}

De acordo com as respostas apresentadas no Questionário de Opinião foi possível observar que os alunos aprovaram a proposta, destacando a importância dos Mapas Conceituais no auxílio para os estudos. Os relatos apontaram que o uso dos mapas de conceitos que compunham o material didático, contribuiu para um melhor entendimento dos conteúdos trabalhados, mediante a organização e a elucidação dos conceitos mais importantes, de forma objetiva e simplificada. Desta forma, verificou-se a eficácia do uso de Mapas Conceituais para compor um material didático potencialmente significativo.

Por meio da análise dos mapas elaborados pelos alunos também foi possível verificar que grande parte desses apresentou uma evolução conceitual progressiva, exibindo um último mapa mais rico de conceitos e proposições válidas que os anteriores. Do mesmo modo, observaram-se indícios que apontaram para uma aprendizagem mais significativa, relativa aos assuntos trabalhados ao longo do semestre. Tais indícios foram elucidados por meio da observação dos critérios classificatórios propostos por Novak e Gowin (1996), nos quais foram analisadas as proposições elaboradas pelos alunos, os níveis hierárquicos, as ligações transversais e exemplos apresentados, verificando-se a efetividade da utilização dos Mapas Conceituais como ferramenta de avaliação da aprendizagem significativa para alunos de um curso profissionalizante de nível médio. Mediante a observação desses critérios, pôde-se aferir que $87 \%$ dos educandos apresentaram uma evolução conceitual significativa ao longo do semestre letivo, demonstrando que o uso de Mapas Conceituais como uma ferramenta pedagógica auxilia no processo de ensino e aprendizagem, fornecendo subsídios para uma aprendizagem mais significativa. 


\section{The Use of Concept Maps as a Teaching and Assessment Tool of Meaningful Learning of Concepts Related to Petroleum Chemistry}

\section{Abstract}

Chemistry teaching is commonly structured around activities that lead to the memorization of information and mechanical repetition of concepts, which may culminate in the limitation of students' learning. Within this context, it is necessary to seek to implement new teaching and learning proposals and strategies, as well as potentially significant materials and instruments, in order to enable the amplification of teaching quality. From this perspective, Concept Maps are presented as flexible and dynamic instruments that can be used in classroom or laboratory. Thus, the main objective of this work was the use of Concept Maps in order to contribute to a more meaningful learning of students of the experimental part of the "Regional Technologies II" subject of the Technical Chemistry Course at the Instituto Federal Fluminense (IFFluminense) campus Campos Centro. The maps were prepared using the CmapTools software, and later attached to the didactic material of two classes of module IV of the Technical Course in Chemistry, which were used during the second semester of 2018. In search of evidence of the effectiveness of the use of Concept Maps to contribute to a more meaningful learning, an Opinion Questionnaire containing mixed questions was introduced in order to detect the students' perception about the teaching instrument used. Concept Maps were also used as assessment tools, which were prepared by the students at three different times, these being, at the beginning of the semester and at the end of the first and second bimesters. These maps were intended to look for clues that would point to more meaningful learning and to ascertain the conceptual evolution of students. Through the analysis of the questionnaires and the Concept Maps prepared by the students, it was observed, in general, a progressive conceptual evolution and signs pointing to a more meaningful learning, indicating that potentially significant materials can contribute to assist in the teaching and learning process.

Keywords: Meaningful Learning. Chemistry teaching. Concept Maps.

\section{Referências}

AUSUBEL, David Paul. The psychology of meaningful verbal learning. New York, Grune and Stratton, 1963.

ARAÚJO, Nelci Reis Sales de; BUENO, Eliana Aparecida Silicz; ALMEIDA, Flaveli Aparecida de Souza; BORSATO, Dionísio. O petróleo e sua destilação: uma abordagem experimental no Ensino Médio utilizando mapas conceituais. Semina: Ciências Exatas e Tecnológicas, Londrina, v. 27, n. 1, p.57-62, jun. 2006. DOI: http://dx.doi.org/10.5433/1679-0375.2006v27n1p57

CAÑAS, Alberto J.; FORD, Kenneth M.; NOVAK, Joseph D.; HAYES, Patrick; REICHHERZER, Thomas; SURI, Niranjan. Online concept maps: enhancing collaborative learning by using technology with concept maps. The Science Teacher, v. 68, n. 4, p. 49-51, 2001.

CAÑAS, Alberto. J.; HILL, Greg; CARFF, R.; SURI, Niranjan; LOTT, James; ESKRIDGE, Thomas C.; GOMEZ, Gloria; ARROYO, Mario; CARVAJAL, Rodrigo. CmapTools: Una rete per mod- 
ellizare e condividere la conoscenza. In: SPAZIANTE, A. (Ed.). La conoscenza come bene pubblico comune: Software, dati, saperi. Torino: CIS-Piemonte, 2004. p. 51-62.

DANTAS Claudio R. da S.; GERMANO, Marcelo G.; MOITA, Filomena M. G. da S. Concept maps as an evaluation tool of concepts construction of energy with high school students. Experiências em Ensino de Ciências, v. 12, n.5, 2017. Disponível em: http://if.ufmt.br/eenci/artigos/ Artigo_ID383/v12_n5_a2017.pdf> Acesso em 08 de Maio de 2020.

FREITAS FILHO, João Rufino de. Mapas conceituais: estratégia pedagógica para construção de conceitos na disciplina química orgânica. Ciências \& Cognição, Rio de Janeiro, v. 12, n. 1, p.86-95, dez. 2007. Disponível em < http://www.cienciasecognicao.org/revista/index.php/cec/article/ view/638> Acesso em 08 de Maio de 2020.

GOLDENBERG, Mirian. A arte de pesquisar: Como fazer pesquisa qualitativa em Ciências Sociais. Rio de Janeiro: Editora Record, 2004.

LIMA, Josiel A.; SAMPAIO, Caroline de G.; BARROSO, Maria Cleide da S.; VASCONCELOS, Ana Karine P.; SARAIVA, Francisco Alberto. Avaliação da aprendizagem em Química com uso de mapas conceituais. Revista Thema, Rio Grande do Sul, v. 14, n. 2, p.37-49, 2017. DOI: http:// dx.doi.org/10.15536/thema.14.2017.37-49.422

MARTINS, Renata Lacerda Caldas; VERDEAUX, Maria de Fátima da Silva; SOUSA, Célia Maria Soares Gomes de. A utilização de diagramas conceituais no ensino de física em nível médio: um estudo em conteúdos de ondulatória, acústica e óptica. Revista Brasileira de Ensino de Física, São Paulo, v. 31, n. 3, p.1-12, set. 2009a. DOI: https://doi.org/10.1590/S1806-11172009005000002.

MARTINS, Renata Lacerda Caldas; LINHARES, Marília Paixão; REIS, Ernesto Macedo. Mapas conceituais como instrumento de avaliação e aprendizagem de conceitos físicos sobre mecânica do vôo. Revista Brasileira de Pesquisa em Educação em Ciências, v. 9, n. 1, 2009b. Disponível em: https://periodicos.ufmg.br/index.php/rbpec/article/view/4007/2571> Acesso em 08 de Maio de 2020.

MOREIRA, Marco Antônio; SOARES, Sabrina; PAULO, Iramaia C. Mapas conceituais como instrumento de avaliação em um curso introdutório de mecânica quântica. Resultados da pesquisa. Revista Brasileira de Ensino de Ciência e Tecnologia, v. 1, n. 3, set./dez. 2008. DOI: 10.3895/S1982-873X2008000300001

MOREIRA, Marco Antônio. Aprendizagem Significativa: um conceito subjacente. Aprendizagem Significativa em Revista, Porto Alegre, v. 1, n. 3, p.25-46, 2011. Disponível em: <https:// lief.if.ufrgs.br/pub/cref/pe_Goulart/Material_de_Apoio/Referencial\%20Teorico\%20-\%20Artigos/ Aprendizagem\%20Significativa.pdf> Acesso em 08 de Maio de 2020.

MOREIRA, Marco Antônio. Aprendizagem significativa, organizadores prévios, mapas conceituais, diagramas $\mathrm{V}$ e unidades potencialmente significativas. Material de apoio para o curso Aprendizagem Significativa no Ensino Superior: Teorias e Estratégias Facilitadoras. PUCPR, v. 2012. Disponível em:<http://www.profjudes.unir.br/uploads/44444444/arquivos/ TAS_1518397339.pdf> Acesso em 08 de Maio de 2020.

MOREIRA, Marco Antônio. Aprendizagem Significativa em mapas conceituais. Textos de Apoio Ao Professor de Física, Porto Alegre, v. 24, n. 6, p.1-49, 2013. Disponível em: http://www.if.ufrgs. br/public/tapf/v24_n6_moreira_.pdf> Acesso em 08 de Maio de 2020. 
MOREIRA, Marco Antônio; ROSA, Paulo. Mapas Conceituais. Caderno Catarinense de Ensino de Física, Porto Alegre, v. 3, n. 1, p.17-25, abr. 1986. DOI: https://doi.org/10.5007/\%25x

NOVAK, Joseth D.; GOWIN, D. Bob. Aprender a aprender. Lisboa: Platano Edições Técnicas, 1996. 212p.

PACHECO, Sabrina Moro Villela; DAMASIO, Felipe. Mapas conceituais e diagramas V: ferramentas para o ensino, a aprendizagem e a avaliação no ensino técnico. Ciências \& Cognição, Santa Catarina, v. 14, n. 2, p.166-193, jul. 2009. Disponível em: < http://www.cienciasecognicao. org/revista/index.php/cec/article/view/148> Acesso em 08 de Maio de 2020.

PELIZZARI, Adriana; KRIEGL, Maria de Lurdes; BARON, Márcia P.; FINCK, Nelcy Teresinha L.; DOROCINSKI, Solange Inês. Teoria da aprendizagem significativa segundo Ausubel. PEC Psicologia Educação e Cultura, Curitiba, v. 2, n. 1, p.37-42, jul. 2002. Disponível em: < http:// portaldoprofessor.mec.gov.br/storage/materiais/0000012381.pdf> Acesso em 08 de Maio de 2020.

PIVATTO, Ms. Wanderley. Aprendizagem significativa: revisão teórica e apresentação de um instrumento para aplicação em sal de aula. Itinerarius Reflectionis, Jataí, v. 2, n. 15, p.1-20, 2013. DOI: https://doi.org/10.5216/rir.v2i15.27795

POLIT, Denise F.; BECK, Cheryl T.; HUNGLER, Bernadette P. Fundamentos de pesquisa em enfermagem: métodos, avaliação e utilização. Trad. de Ana Thorell. 5. ed. Porto Alegre: Artmed, 2004.

ROCHA, Cecília Elenir dos S.; SPOHR, Carla Beatriz. O Uso de Mapas Conceituais como Instrumento Didático para Identificar Indícios de Aprendizagem Significativa em Diferentes Níveis de Ensino. Investigações em Ensino de Ciências, Bauru, v. 21, n. 3, p. 23-52, dez. 2016. DOI: http://dx.doi.org/10.22600/1518-8795.ienci2016v21n3p23

RUIZ-MORENO, Lidia; SONZOGNO, Maria Cecília; BATISTA, Sylvia Helena da S.; BATISTA, Nildo A. Mapa Conceitual: ensaiando critérios de análise. Ciência \& Educação (Bauru), v. 13, n. 3, p. 453-463, sept./dec. 2007. DOI: https://doi.org/10.1590/S1516-73132007000300012

SANTOS, A. O.; SILVA, R.P.; ANDRADE, D.; LIMA, J. P. M. Dificuldades e motivações de aprendizagem em Química de alunos do ensino médio investigadas em ações do (PIBID/UFS/Química). Scientia Plena, São Cristóvão, v. 9, n. 7, p.2-6, 2013. Disponível em: <https://www.scientiaplena. org.br/sp/article/view/1517/812> Acesso em 08 de Maio de 2020.

SILVEIRA, Denise Tolfo; CÓRDOVA, Fernanda Peixoto. A pesquisa científica. In: GERHARDT, Tatiana Engel; SILVEIRA, Denise Tolfo. Métodos de Pesquisa. $1^{\mathbf{a}}$ edição. Porto Alegre: Editora da UFRGS, 2009.

STRUCHINER, Miriam; VIEIRA, Alexandre Rezende; RICCIARDI, Regina Maria Vieira. Análise do conhecimento e das concepções sobre saúde oral de alunos de odontologia: avaliação por meio de mapas conceituais. Cadernos de Saúde Pública, Rio de Janeiro, v. 15, n. 2, p.55-68, 1999. DOI: https://doi.org/10.1590/S0102-311X1999000600007

TRINDADE, José Odair da; HARTWIG, Dácio Rodney. Uso Combinado de Mapas Conceituais e Estratégias Diversificadas de Ensino: Uma Análise Inicial das Ligações Químicas. Química Nova na Escola, São Paulo, v. 34, n. 2, p. 83-91, mai. 2012. Disponível em: http://www.educadores. diaadia.pr.gov.br/arquivos/File/dezembro2012/quimica_artigos/mapas_conceituais.pdf> Acesso em 08 de Maio de 2020. 